\title{
Rooibos (Aspalathus linearis) and its Major Flavonoids - Potential Against Oxidative Stress-Induced Conditions
}

\author{
Olawale R. Ajuwon, Jeanine L. Marnewick and Lester M. Davids
}

Additional information is available at the end of the chapter

http://dx.doi.org/10.5772/61614

\begin{abstract}
Reactive species are products of normal cellular metabolism and may be deleterious or beneficial. At low/moderate concentrations, reactive species are involved in physiological roles including cell signalling, defense against infectious agents and mitogenic responses. However, unbalanced defense mechanism of antioxidants, overproduction of reactive species or incorporation of free radicals into the living system from the environment may result in oxidative stress, a deleterious process that can lead to damage of important cell structures, including lipids and membranes, proteins and nucleic acids. The role of oxidative stress as a contributing factor in the pathophysiology of various diseases is increasingly being recognized, and augmenting the oxidative defense capacity of the cell through the intake of antioxidants as a way of preventing free radical-mediated cellular injuries is becoming a popular strategy. Much attention is being focused on the health beneficial role of phenolic phytochemicals derived from plants. They are considered to play an important role as physiologically functional foods and for the prevention of clinical conditions related to oxidative stress, even though their modes of action may still not be fully understood. Rooibos (Aspalathus linearis) is a popular South African tisane enjoyed for its taste and aroma. Rooibos has been made in the Cederberg mountain region of South Africa for generations and has been used medicinally for alleviation of allergies, asthma, infantile colic and skin problems. The potential antioxidative, immune-modulating, chemopreventive and chemotherapeutic actions of rooibos have been reported in several studies. This review provides a comprehensive data on the current knowledge of the biological and chemotherapeutic activity of rooibos and its major flavonoids. Most recent in vitro and in vivo (animal and human) studies were conducted with special attention paid to clinical conditions in which oxidative stress has been implicated. The conclusion described directions for future rooibos research to establish its activity and utility as a human chemopreventive and therapeutic agent.
\end{abstract}

Keywords: Antioxidant, Chemoprevention, Oxidative stress, reactive oxygen species, Rooibos 


\section{Introduction}

Oxidative stress results when there is a disturbance in normal cellular and molecular function as a result of an imbalance between the production of various oxidizing chemical species (prooxidants) and natural antioxidant ability of cells in favour of the former. Pro-oxidants are made up primarily of free radicals, which are chemical species (molecule, ion or atom) that contains an unpaired or an odd electron in their outer orbit. As a result of the presence of unpaired electrons, free radicals are usually very reactive and highly unstable [1,2]. Free radicals target macromolecules in their proximity for their electrons, thereby oxidizing them and generating other free radicals. If the macromolecules targeted are important parts of the cellular structure such as nucleic acids, proteins and lipids, considerable oxidative injury can occur [3]. Free radicals can be derived from four elements, including oxygen, nitrogen, sulphur and chlorine, thereby creating reactive oxygen species (ROS), reactive nitrogen species (RNS), reactive sulphur species (RSS) and reactive chlorine species (RCS). The ROS and RNS are the two main families of relevant pro-oxidants in biology and medicine. Examples of reactive oxygen species are superoxide $\left(\mathrm{O}_{2}{ }^{--}\right)$, hydroxyl radical $\left(\mathrm{OH}^{*}\right)$, singlet oxygen $\left({ }^{1} \mathrm{O}_{2}{ }^{\circ}\right)$ and peroxyl radical (ROO'), while examples of reactive nitrogen species include nitric oxide (NO) and nitrogen dioxide $\left(\mathrm{NO}_{2}\right)$. Apart from the reactive-free radical species, there are also non-radical reactive species which, though do not contain unpaired electrons, are either oxidizing agents or easily converted to free radicals. Examples are hydrogen peroxide $\left(\mathrm{H}_{2} \mathrm{O}_{2}\right)$, organic peroxides such as lipid hydroperoxides $(\mathrm{ROOH})$, hypochlorous acid $(\mathrm{HOCl})$ and peroxynitrite (ONOO $)$ [4-6]. ROS and RNS often act together to create a state of oxidative stress, as a result of either depletion of cellular antioxidant defense molecules or overproduction of the reactive species.

\section{Generation and interactions of reactive oxygen species}

Reactive oxygen species can be generated from many sources, which can be either endogenous or exogenous. Table 1 shows some major endogenous and exogenous sources of reactive species.

\begin{tabular}{ll}
\hline Endogenous sources & Exogenous sources \\
\hline Mitochondrial electron transport chain & Radiation (UV light, X-ray and $\gamma$-radiation) \\
Neutrophils and macrophages during inflammation & Environmental pollutants and toxins \\
Xanthine oxidoreductase, NADPH oxidase & Cigarette smoke, excessive alcohol, high-calorie diet \\
Microsomal oxidation in endoplasmic reticulum & Heavy metals \\
Myeloperoxidase (Phagocytes) & Infectious agent \\
Lipoxygenase, cyclooxygenases, prostaglandin synthase & Strenuous exercise \\
\hline
\end{tabular}

Table 1. Endogenous and exogenous sources of reactive species 
Most ROS are generated via endogenous sources as by-products of normal physiological and metabolic reactions such as energy generation through the mitochondrial electron transport chain reaction and protein assemblage by the endoplasmic reticulum [5,7]. The superoxide radical $\left(\mathrm{O}_{2}{ }^{-}\right)$is considered as the primary $\mathrm{ROS}$ and it can further interact with other molecules either directly or prevalently through enzyme- or metal-catalysed processes to generate secondary ROS [5,8]. The superoxide anion is formed mostly within the mitochondria of a cell during the electron transport chain reaction. Impairment of the electron transport mechanism because of damage to mitochondria either during pathophysiological conditions or during mitochondrial dysfunction results in ROS formation. The electron transport chain is made up of five multienzyme complexes, which are responsible for ATP generation and maintenance of mitochondrial membrane potential. The major site of ROS production is assumed to be complexes I and III [9]; however, ROS can also be generated by other electron complexes, as well as by other mitochondrial enzymes [10]. During energy transduction, there is a premature leakage of electrons to molecular oxygen at complexes I and III forming superoxide anion radical $[5,6,11]$. Xanthine oxidase is another source of superoxide radical. The enzyme catalyses a one-electron as well as a two-electron reduction of oxygen to form $\mathrm{O}_{2}{ }^{--}$or $\mathrm{H}_{2} \mathrm{O}_{2}$, with itself being converted to uric acid [12]. Cyclooxygenase, lipoxygenase and cytochrome P450 are other enzymes that have been proposed to generate ROS. The primary function of these enzyme systems is not to generate ROS; however, as is the case with the mitochondria, a dysfunction of these systems in diseases or environmental toxicity generates ROS as a byproduct. The superoxide anion radical produced as a result of a one-electron reduction of molecular oxygen in the mitochondria is a relatively stable intermediate and its dismutation by the enzyme manganese superoxide dismutase (MnSOD) will result in the formation of $\mathrm{H}_{2} \mathrm{O}_{2}$ [13]. Protein assemblage by the endoplasmic reticulum, mediated by the enzyme protein disulphide isomerase and oxidoreductin 1 , as well as fatty acid degradation by peroxisomes, also accounts for $\mathrm{O}_{2}{ }^{--}$, which is dismutated to $\mathrm{H}_{2} \mathrm{O}_{2}$ by copper/zinc superoxide dismutase $(\mathrm{Cu} /$ $\mathrm{ZnSOD}$ ) [14]. The $\mathrm{H}_{2} \mathrm{O}_{2}$ produced is a non-radical molecule and it is normally neutralized by $\mathrm{H}_{2} \mathrm{O}_{2}$-removing enzymes, catalase and the glutaredoxin enzyme system (consisting of glutathione peroxidase, glutathione reductase and glutathione (GSH)) to water and molecular oxygen [15]. Glutathione peroxidase uses reduced GSH as a substrate and it is converted to the oxidized form (GSSG). Reduced glutathione is regenerated in a reaction catalysed by glutathione reductase with subsequent oxidation of NADPH. However, during a period of iron overload (e.g. conditions of haemochromatosis, haemolytic anaemia and haemodialysis), in the presence of high amounts of $\mathrm{H}_{2} \mathrm{O}_{2}$, heavy metals such as iron (Fe) or copper $(\mathrm{Cu})$ are freed from iron-containing molecules and there is a subsequent interaction of $\mathrm{O}_{2}{ }^{--}$and $\mathrm{H}_{2} \mathrm{O}_{2}$ in a Haber-Weiss reaction or $\mathrm{Fe}^{2+}\left(\mathrm{Cu}^{2+}\right)$-driven cleavage of $\mathrm{H}_{2} \mathrm{O}_{2}$ in a Fenton reaction to generate the highly reactive hydroxyl radical $(\cdot \mathrm{OH})$ as shown in Figure $1[12,13,16]$. The $\cdot \mathrm{OH}$ radical is highly reactive because of its very short half-life ( $<1 \mathrm{~ns})$; thus, in vivo, it can react with macromolecules such as lipids, proteins and nucleic acids in the vicinity of its site of formation, resulting in oxidative damage to these important cellular components [16]. Other oxygenderived free radicals that can be formed in vivo are the peroxyl radicals (ROO') (Figure 1) which are involved in DNA damage and protein backbone modification and have also been found to synergistically enhance the induction of DNA damage by superoxide [7]. 
Reactive nitrogen species are nitrogen-centred free radicals and include the nitric oxide radical $(\mathrm{NO})$, nitrosonium cation $\left(\mathrm{NO}_{2}\right)$, nitroxyl anion $\left(\mathrm{NO}^{-}\right)$, nitrous oxide radical $\left(\mathrm{NO}_{2}{ }^{-}\right)$and peroxynitrite $\left(\mathrm{ONOO}^{-}\right)$. The NO radical is the precursor of other RNS and is produced in higher organisms by the oxidation of one of the terminal guanido-nitrogen atoms of Larginine in a reaction catalysed by nitric oxide synthase (NOS) $[17,18]$. The NOS family includes endothelial NOS (eNOS) and neuronal NOS (nNOS), both of which are constitutively expressed isoforms, as well as the transcriptionally regulated isoform, inducible NOS (iNOS), which has been shown to play an important role in host defense [19-21]. Overproduction of the RNS above the ability of the cell to neutralize them is known as nitrosative stress and may lead to nitrosylation reactions that can alter the structure of proteins and so inhibit their normal function [7]. Oxidative burst during inflammatory processes triggers the formation of both superoxide and nitric oxide radical from immune cells and they react together to produce the highly reactive peroxynitrite anion radical which is a potent oxidizing agent that can cause DNA fragmentation $[5,7,22]$. Other nitrating agents include the nitrosonium cation formed in a myeloperoxidase-catalysed reaction involving nitrite $\left(\mathrm{NO}_{2}^{-}\right)$and hydrogen peroxide $[23,24]$ and nitroso-peroxocarbonate $\left(\mathrm{ONO}-\mathrm{OCO}_{2}^{-}\right)$formed via the reaction of $\mathrm{CO}_{2}$ with $\mathrm{ONOO}^{-}$ $[25,26]$. A recent study has also shown that lipid peroxyl radicals are able to promote tyrosine nitration by inducing tyrosine oxidation and also by reacting with $\mathrm{NO}_{2}{ }^{\cdot}$ to produce nitrosonium cation $\left(\cdot \mathrm{NO}_{2}\right)[27]$.

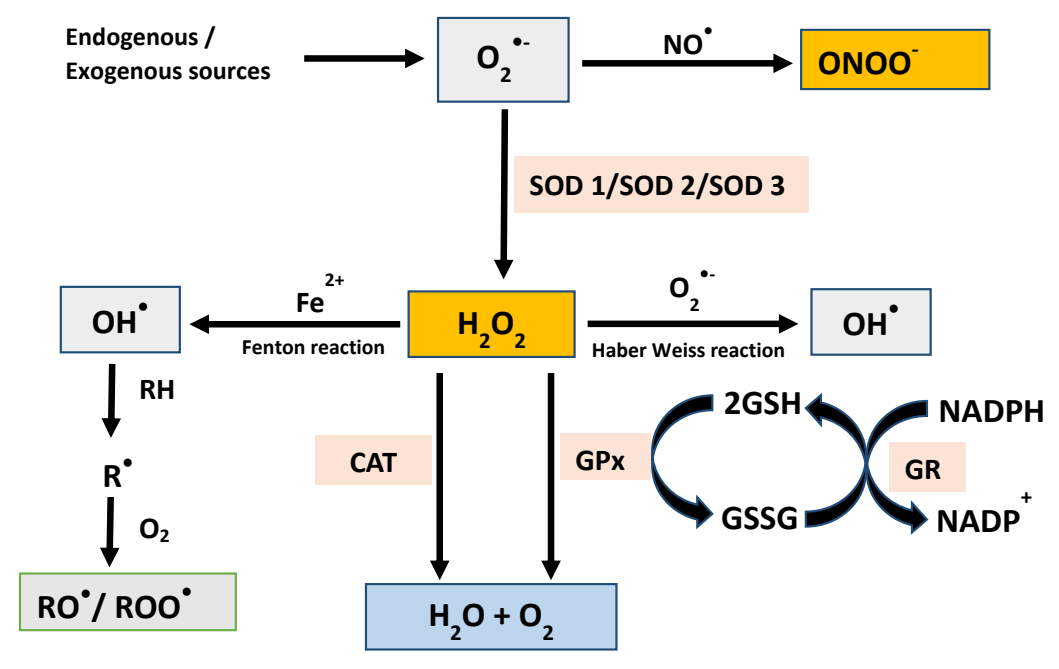

Figure 1. Sources and generation of different reactive oxygen species. CAT, catalase; GPx, glutathione peroxidase; GR, glutathione reductase; SOD, superoxide dismutase; $\mathrm{RH}$, lipid membrane; $\mathrm{R}$, alkyl radical

Hypochlorous acid $(\mathrm{HOCl})$ is a non-radical reactive chloride species involved in oxidation and chlorination reactions. It is usually generated via a myeloperoxidase-catalysed reaction involving $\mathrm{H}^{+}$, chloride ion and $\mathrm{H}_{2} \mathrm{O}_{2}$ by the activated neutrophils [28,29]. Evidence has shown that $\mathrm{HOCl}$ can oxidize thiols and other biological molecules, and chlorinate amines, choles- 
terol, unsaturated lipids, as well as DNA [28,30]. Although sulphur is considered a component of cellular antioxidant systems, emerging facts are indicating that reactive sulphur species (RSS) with similar stressor properties to ROS are generated under condition of oxidative stress when primary stressors react with cellular components. These reactive sulphur species are involved in protein activity modulation via thiolation reactions. An important example of an RSS implicated in physiological process is the thiyl radical (RS) formed from a one-electron oxidation of a thiol group as an intermediate to the production of a disulphide, or via the reaction of sulphydryl groups with ROS such as superoxide radical [31,32]. Thiyl radicals participate in a series of radical chain reactions that generate other highly reactive sulphurcentred radicals. For example, a thiyl radical reacts with a thiolate to form the disulphide radical anion (RSSR ${ }^{-}$) and with molecular oxygen to form the thiyl peroxyl radical (RSOO). Furthermore, disulphide radical anions interact with molecular oxygen to generate the disulphide (RSSR) and the superoxide radical [31]. These reactions underline the close relationship between RSS and ROS.

\section{Physiological importance of reactive oxygen species}

Reactive oxygen and nitrogen species have generally been considered as being highly reactive and cytotoxic molecules; however, accumulating evidence has shown that besides their deleterious effects, ROS participates in physiological processes in a well-controlled manner. Physiological sources of ROS in the cell are many, but in a number of cells, ROS generated by the NADPH oxidase enzyme are those implicated in important physiological responses, such as defense against environmental pathogens or in cell signalling [33]. Reactive oxygen and nitrogen species are able to influence physiological processes because of their ability to modify the activity of key protein molecules containing domains sensitive to redox conditions. Reversible oxidation of the target domain results in the initiation of coupled events, such as the modification of the activity of downstream enzymes and/or transcription factors. Recent evidence has shown that at moderate concentrations, nitric oxide (NO), superoxide anion and related reactive species play an important role as regulatory mediators in cell-signalling processes and that many of the ROS-mediated responses actually protect the cells against oxidative stress and re-establish redox balance [4].

Accumulating evidence suggests that oxidants may be important regulators of the cellular response under hypoxic conditions (oxygen concentrations between 1\% and 5\%). Although the molecular basis for this is still obscure, nonetheless, there are suggestions that the release of ROS under these conditions functions as an important physiological regulator of hypoxiainducible factor $1 \alpha$ (HIF- $1 \alpha$ ), which, under low oxygen conditions, respond to a rise in ROS and then feedback and inhibit the production of ROS levels [10,34-36]. Other HIF-1 $\alpha$ activities include the transcriptional regulation of metabolic enzymes such as lactate dehydrogenase A and pyruvate dehydrogenase kinase 1 , which control the flow of carbon substrates into the mitochondria $[37,38]$. Other studies have also shown that HIF-1 $\alpha$ regulates the expression of certain cytochrome components directly and also regulates specific microRNAs that in turn regulate the expression of components of the electron transport chain $[10,39,40]$. 
ROS mediate inflammatory responses in a number of ways. In an inflammatory environment, activated neutrophils and macrophages produce large quantities of superoxide radicals and other ROS via the phagocytic isoform of NADPH oxidase for the destruction of intracellular microbes [5,41]. Recent evidence has shown that mitochondrial ROS also contribute to the phagocytic response of the innate immune system as a result of the activation of a subset of Toll-like receptors (TLR1, TLR2 and TLR4) [42]. Mitochondrial ROS (mROS) have also been suggested to be involved in the activation of the inflammasome, thus acting as important signalling molecules to regulate inflammatory responses. Specifically, mROS have been implicated in the activation of NLRP3 (NOD-like receptor, pyrin domain-containing 3) receptor which senses a wide range of damage signals, including environmental irritants, microorganisms, as well as endogenous danger signals such as ATP and uric acid. When activated, NLRP3 forms a high-molecular-weight intracellular complex with a number of other protein partners to regulate the maturation and secretion of pro-inflammatory cytokines such as IL-1 $\beta[10,43-45]$.

Another physiological role of ROS is the regulation of vascular tone by cGMP. Soluble guanylate cyclase (sGC) is a heterodimeric protein which catalyses the formation of cGMP. Soluble guanylate cyclase can be activated by both $\mathrm{NO}$ and $\mathrm{H}_{2} \mathrm{O}_{2}$, with $\mathrm{NO} \cdot$ activating sGC by binding to its $\mathrm{Fe}^{2+}$-haem groups resulting in a conformational change at $\mathrm{Fe}^{2+}$ that activates the enzyme. The cGMP formed is used as an intracellular amplifier and a second messenger to modulate the function of protein kinases, ion channels and other physiologically important targets, including smooth muscle tone regulation and platelet adhesion inhibition [5]. Reactive oxygen and nitrogen species have been implicated in the regulation of autophagy and apoptosis. Mitochondria-generated ROS regulate autophagy by the direct regulation of Atg4 (autophagy-related gene 4) activity [46,47]. ROS also played an important role in the release of cytochrome $\mathrm{c}$ and other pro-apoptotic proteins, which can trigger caspase activation and apoptosis. Therefore, small molecules like ROS can affect the complex networks of proteins mediating the induction and execution of cell death [13].

\section{Consequences of oxidative stress}

Oxidative attack by ROS is manifested as damage to nucleic acid bases, lipids and proteins, which can severely compromise cell health and viability or induce a variety of cellular responses through the generation of secondary reactive species, ultimately leading to cell death by necrosis or apoptosis [48]. Macromolecular damage via oxidative and/or nitrosative stress, if unchecked, can theoretically contribute to disease development, and an increasing amount of evidence suggests that oxidative and/or nitrosative stress is linked to the pathophysiologic mechanisms of a myriad of human diseases [3,6,48-50].

\subsection{Lipid peroxidation}

Lipid peroxidation refers to the oxidative degradation of lipids that occur when ROS attack lipids and extract a hydrogen atom from a methylene carbon in the side chain, and is one of 
the major outcomes of free radical-mediated injury. The cell membrane is one of the most susceptible sites to ROS damage because the polyunsaturated fatty acid (PUFA) residues of phospholipids are very sensitive to oxidation. The process of lipid peroxidation occurs in three stages: initiation, propagation and termination. Reactive species such as $\mathrm{O}_{2}{ }^{--}, \mathrm{OH} \cdot \mathrm{RCOO}$ and ONOO are all potent initiators of lipid peroxidation. During initiation, the fatty acid containing the double-bonded carbon chains is oxidized by a free radical to produce a lipid radical which stabilizes itself by reacting with oxygen to produce the peroxyl radical, which can then oxidize a neighbouring fatty acid to become a stable hydroperoxide. The oxidized fatty acid neighbour becomes a lipid radical, which propagates the oxidation process across the lipid membrane $[7,16]$. The lipid hydroperoxides formed may then be converted into conjugated dienes which are unstable and generate a variety of relatively stable end products, mainly aldehydic by-products, such as malondialdehyde (MDA) and more reactive $\alpha$-, $\beta$-unsaturated aldehydes, such as trans-4-hydroxy-2-nonenal (4-HNE) and 2-propenal (acrolein) [48,51-54]. Isoprostanes and neuroprostanes and more recently neurofurans are other products that have been derived from the endocyclization of lipid hyroperoxyl radicals [55-59], and the evaluation of these end products has been used as an index to determine the extent of oxidative damage in cells.

\subsection{Oxidative protein damage}

Proteins are primarily responsible for most functional processes within cells and are thus highly abundant in biological systems, making them important targets of ROS attack. The attack of ROS on the polypeptide backbone is initiated by an $\cdot \mathrm{OH}$-dependent abstraction of the $\alpha$-hydrogen atom from an amino acid residue to form a carbon-centred radical. Under aerobic conditions, the carbon-centred radical readily interacts with molecular oxygen to form peroxyl radicals, which react with the protonated form of superoxide $\left(\mathrm{HO}_{2}{ }^{\circ}\right)$ and are converted to the alkyl peroxides $[5,60]$. Attack by ROS on proteins may lead to the oxidation of amino acid residue side chains, as well as oxidation of the protein backbone and formation of proteinprotein cross-linkages. Consequently, protein fragmentation and generation of many protein oxidation products, which can cause damage to other biomolecules, may occur [53,61,62]. All amino acids within proteins may be attacked by reactive species (including ROS, RNS and electrophiles); however, the thiol group of cysteine are the most susceptible. Nevertheless, generally to a lesser extent than cysteine, sulphur-containing methionine and the aromatic amino acids tyrosine and tryptophan are also susceptible to oxidation [63].The susceptibility of the thiol group arises from the unique chemistry of cysteine, which confers on the thiol group specialized properties including nucleophilicity, high-affinity metal binding and/or ability to form disulphide bonds. The thiol group of cysteine is reported to be ionizable, generating a negatively charged thiolate group after deprotonation, boosting its reactivity [64]. The functional roles played by thiol groups are linked to this reactivity. Apart from having high affinities for metals, thiols may be subjected to alkylation by electrophiles (generated by xenobiotics), oxidation by reactive oxygen species and nitration by reactive nitrogen species [64-67]. These not only make the thiols versatile in their biological roles but may also lead to post-translational modifications that alter functions and subvert normal biology. 
Every level of protein structure, from primary to quaternary (if multimeric proteins), may be altered when proteins are exposed to oxidative attack by ROS, causing major physical changes in protein structure [48]. Because most protein damage is irreparable, oxidative changes to the structure of protein can have a wide range of functional consequences including affecting the function of receptors, enzymes and transport proteins as well as generating new antigens that can provoke immune responses [68]. Secondary damage to other biomolecules can also result in the inactivation of DNA repair enzymes and loss of fidelity of damaged DNA polymerases in replicating DNA [68,69]. Although oxidized proteins are usually degraded by the proteosomal system and the lysosome-macroautophagy pathway, however, the degradation of damaged proteins may not be completely efficient, resulting in the formation of functionally inactive protein aggregates, which accumulate with age in separate compartments within cells or in the extracellular environment [63,70-72]. It is also possible that the proteolytic systems responsible for the removal of oxidized proteins may be impaired by oxidative stress itself, thereby accelerating the accumulation of damaged carbonylated-aggregating proteins [73]. Protein aggregates can be highly cytotoxic [74], and increased levels of carbonylated aggregates have been observed in patients with age-related disorders such as Parkinson disease, Alzheimer's disease and cancer [72].

\subsection{Oxidative DNA damage}

Reactive oxygen species, especially $\mathrm{OH}$ ' radical generated during oxidative stress, can react with and cause modifications in all the components of the DNA molecule (the purine and pyrimidine bases and deoxyribose sugar backbone), causing damage such as base or sugar lesions, single-strand breaks, double-strand breaks, abasic site formation and DNA-DNA or DNA-protein cross-links $[3,53,75]$. Reports have indicated that reactive oxygen and nitrogen species alone generate several kinds of single-strand breaks and more than 70 oxidative base and sugar products in DNA [76,77]. It has been estimated that the frequency of oxidative DNA damage in human cells is $10^{4}$ lesions/cell/day [78,79]. Although hydrogen peroxide is less reactive, it is more readily diffusible and thus more likely to be involved in the formation of oxidized bases through Fenton and Haber-Weiss reactions [60,80,81]. Oxidative damage not repaired before DNA replication may cause cell death, DNA mutation, replication errors and genomic instability [7,82-84]. Reports by Halliwell [85] and Valko et al. [8] indicated that oxidative DNA damage may be related to an increased risk of cancer development later in life. DNA can also undergo nitrative damage as a result of attack of reactive nitrogen species (RNS) on DNA bases to form 8-nitroguanine, a mutagenic DNA lesion that can preferentially lead to G-T transversions, and its formation has been observed in human samples [86]. Attack on DNA by aldehydic products of lipid peroxidation such as acrolein and 4-HNE can lead to the formation of bulky exocyclic adducts, which can promote DNA-DNA and DNA-protein crosslinking and impair transcription factors binding [87-89].

The most commonly used biomarker of DNA damage is the concentration of the nucleoside, 8-hydroxy-2'-deoxyguanosine (8-OHdG), which has been found to be mutagenic in bacterial and in mammalian cells $[3,50,90,91]$. Numerous reports have shown that urinary levels of 8 OHdG were elevated in humans with various malignancies [92-98] and also in experimental animal models of tumours [99-103]. 


\section{Endogenous antioxidant defense system}

Under normal circumstances, eukaryotic cells have evolved a defense mechanism to limit free radicals and the damage caused by them. These include systems based on the presence of antioxidant molecules, the repair of injured molecules and the removal of damaged molecules. The antioxidant defense system can be endogenous and/or exogenous. The endogenous system is made up of a network of antioxidant enzymes including superoxide dismutase (SOD), catalase (CAT), glutathione peroxidase (GPx) and the glutaredoxin and peroxiredoxin system as well as low-molecular-weight antioxidant molecules such as glutathione. Superoxide dismutase catalyses the dismutation of superoxide anion, converting it to molecular oxygen and $\mathrm{H}_{2} \mathrm{O}_{2}$. There are three isoforms of the SOD family and they all used a transition metal at their active site. There is a CuZnSOD form in the cytosol and the intermembrane mitochondrial compartment [104], a MnSOD in the mitochondrial matrix and another form in the extracellular compartment (e.g. blood) [105].

Although less reactive than the $\mathrm{O}_{2}{ }^{--}$anion, the $\mathrm{H}_{2} \mathrm{O}_{2}$ must still be rapidly removed, and this can be accomplished by the enzymes CAT and GPx working coordinately. Catalase removes $\mathrm{H}_{2} \mathrm{O}_{2}$ at a high rate but shows low affinity for the peroxide; thus, it should be most useful during the peak of $\mathrm{H}_{2} \mathrm{O}_{2}$ production or accumulation [105]. Evidence has shown that this peak should occur in vivo since acatalasaemia (i.e. disorder caused by lack of catalase) increases oxidative stress and induces certain pathologies in humans [106]. Glutathione peroxidase may be present in the selenium- and non-selenium-dependent forms, and it has been shown that there are at least five selenium-containing GPxs in humans $[107,108]$ whose activities may be manipulated by changing dietary selenium levels [109]. The isoforms are the ubiquitously expressed cytosolic GPx (GPx-1) and phospholipid hydroperoxide GPx (GPx-4), epitheliumspecific gastrointestinal GPx (GPx-2), secreted plasma GPX (GPx-3) and GPx-6 found in the olfactory epithelium and embryonic tissue [108,110,111]. All the GPx isoforms (GPx 1-4 and GPx-6) can metabolize $\mathrm{H}_{2} \mathrm{O}_{2}$ and soluble fatty acid hydroperoxides; however, only GPx-4 can metabolize complex phospholipid hydroperoxides [107]. The phospholipid hydroperoxide GPx-4 also differs from other isoforms in that it is a monomer while others are tetrameric proteins [109]. Glutathione peroxidases use the reducing power of GSH (and other thiols, such as thioredoxin) to decompose $\mathrm{H}_{2} \mathrm{O}_{2}$, and it is the sulphydryl moiety of the cysteine residue that supplies the reducing equivalent for GPx activity. Two molecules of GSH are oxidized for every one molecule of $\mathrm{H}_{2} \mathrm{O}_{2}$ decomposed, resulting in the formation of GSSG, which can be rereduced back to two molecules of GSH by glutathione reductase.

Various low-molecular-weight endogenous non-enzymatic antioxidants are found in animal and human tissues. These are usually depleted when they react with ROS, but are actually recycled back to the antioxidant form due to reduction by other molecules. Because of their low molecular weight, they are able to eliminate ROS at sites that much larger enzymes cannot access [105]. Reduced glutathione (GSH), thioredoxin and ascorbate are the main low-molecularweight hydrophilic non-enzymatic antioxidant molecules in the cell. Glutathione (L- $\gamma-$ glutamyl-L-cysteinylglycine) is the predominant intracellular non-protein thiol in eukaryotic cells. It possesses strong antioxidative properties and consequently plays a crucial role in 
intracellular protection against compounds such as ROS and other free radicals [112-114]. It functions as a nucleophile to form conjugates with many xenobiotics and/or their metabolites and can also serve as a reductant in the metabolism of hydrogen peroxides and other organic hydroperoxides [112,113,115-118]. During interaction with free radicals, the-SH group of GSH becomes oxidized, leading to the formation of corresponding disulphide compound (GSSG). Thus, a depletion of GSH is usually associated with an increase in GSSG concentration, and the ratio between reduced and oxidized forms of GSH serves as an important indicator of the redox environment [119-121]. The thioredoxin system is another major intracellular antioxidant system and comprises thioredoxin (Trx), thioredoxin reductase (TrxR) and NADPH. It is an oxidoreductase with a redox-active disulphide/dithiol at the active site [105,122]. Thioredoxin is cytoprotective against oxidative stress either directly by quenching singlet oxygen and scavenging hydroxyl radical or indirectly by reducing oxidized ROS-targeted proteins in cooperation with peroxiredoxin/thioredoxin-dependent peroxidases $[123,124]$.

\section{Exogenous antioxidant defenses: diet-derived compounds}

Endogenous antioxidant defense system may not be sufficient when the formation of ROS and other free radicals is excessive, especially during pathophysiological conditions. Therefore, additional protective mechanism via exogenous/dietary antioxidants may be required. Wellknown diet-derived antioxidants are vitamins $\mathrm{C}$ (ascorbate), $\mathrm{E}$ and $\mathrm{A}$, as well as carotenoids. Next to glutathione, ascorbate is the other most abundant reduced non-enzymatic antioxidant in cells. It is endogenously synthesized and maintained at high levels in tissues (about 1 $\mathrm{mM}$ in rats), but in primates (including human), guinea pigs, fruit-eating bats and many bird species, it is obtained through diet [125]. Ascorbate can scavenge ROS and other free radicals by readily donating an electron to potentially damaging radicals such as hydroxyl $\left(\mathrm{OH}^{*}\right)$, alkoxyl (RO'), peroxyl (LOO'), thiol radical (GS') and tocopheroxyl radicals (TO') becoming oxidized to the ascorbate radical $\left(\mathrm{Asc}^{-{ }^{-}}\right)$during the process $[126,127]$. Ascorbate is regenerated from the Asc $^{-}$by the action of (i) NADH- and NADPH-dependent dehydroascorbate reductase [128130], (ii) GSH-dependent dehydroascorbate reductase [131] or (iii) pH-dependent disproportionation reaction, which results in the formation of ascorbate and dehydroascorbate [132,133]. Reports have shown that GSH and ascorbate interact cooperatively in vivo to cope with ROS and that ascorbate serves as a co-antioxidant with vitamin E invivo to protect LDL from detectable oxidative damage induced by aqueous peroxyl radicals [134].

Vitamin E and carotenoids are the most important antioxidants in the lipophilic environment of the cell. There are eight known isoforms of the vitamin $E$ family, comprising $\alpha-, \beta-, \gamma-$ and $\delta$-tocopherol and the corresponding tocotrienols [135-137]. Because of the presence of an -OH group on the chromanol ring of vitamin $\mathrm{E}$, it is able to function as an antioxidant and reduces lipid peroxyl groups to hydroperoxides, thus terminating the propagation of lipid peroxidation $[105,138]$. Empirical evidence for carotenoids being important antioxidants in vivo is weak $[105,139]$. Recent reports on birds showed that carotenoids have a very low contribution to protection against oxidative damage under stressful conditions [140-144]. Many human trials where carotenoids and other dietary antioxidants (vitamin C and E) were administered singly 
or together did not show any positive effect and even contributed to mortality among study subjects [145-148].

In addition to the vitamins and carotenoids, plant-derived phenolics are other exogenous source of antioxidant defense compounds. The intake of exogenous antioxidants from teas, fruits, vegetables and spices is of nutritional interest since it has been associated with the modulation of oxidative stress and cellular damage, as well as with the provision of substantial health benefits. Diet has been known as a risk factor for chronic diseases for many years, and the upsurge in cases of chronic diseases worldwide in the past decades has been attributed in part to the change from traditional, largely plant-based diet to the high-fat, energy-dense diets with substantial content of animal fat [149]. In addition, the Mediterranean diet characterized by frequent consumption of fruits, vegetables, legumes, cereals and fish and low in meat and cheese is positively associated with a reduced risk of most chronic diseases including cardiovascular diseases (CVDs), diabetes and cancer [150]. Fruits, vegetables, spices and teas are excellent sources of fibre, vitamins and minerals, but they also contain components such as polyphenols, terpenes, alkaloids and phenolics, which may provide substantial health benefits beyond basic nutritional functions [151]. Disease prevention using whole plant extracts, or isolated compounds from plant (phytochemicals), is gaining more scientific attention worldwide, because it is a cost-effective alternative to orthodox treatment, and the phytochemicals are presumed from anecdotal evidence to be safe, with low toxicity and general acceptance $[152,153]$. Whole plant extracts as well as isolated molecules have been shown to possess antioxidant, anti-inflammatory, anticancer and tumour inhibitory effects. The health-promoting effects of these plants are suggested to be due to the polyphenolic antioxidant molecules that they contain. Plants often contain different polyphenolic phytochemicals, and it is the general assumption that the observed health effects of these plants may be due to the additive and/or synergistic effects of the complex mixture of these phytochemicals rather than the effect of a single molecule [154-156].

\section{Plant phenolics and polyphenols}

With an excess of 8000 phenolic structures being reported, plant phenolics are one of the most widely dispersed groups of phytochemicals in the plant kingdom. Structurally, they are characterized by having at least one aromatic ring with one or more hydroxyl groups and can range from low-molecular-weight, simple aromatic-ring compounds to large and complex tannins and derived polyphenols $[157,158]$. Phenolics are secondary metabolites produced during diverse physiological processes in the plants, such as growth, lignification, pigmentation, pollination and defense against pathogens, predators and environmental stress [159]. According to Crozier et al. [157], plant phenolics occurring naturally in healthy plant tissue can be classified into (i) flavonoids and (ii) non-flavonoids. The major non-flavonoids of dietary significance include phenolic acids, phenolic alcohols, stilbenes and the lignans. Flavonoids are widely distributed in food and beverages of plant origin, including teas, fruits, vegetables, spices, cocoa and wine that form part of human diet. In plants, they play key roles in growth and development [160], plant-insect interactions [161] and protection against harmful 
radiation by absorbing ultraviolet $\mathrm{B}$ (UVB) and scavenging ROS generated by UVB irradiation $[162,163]$. Flavonoids are known to provide health-promoting effects in humans who consume them. Reports have shown that flavonoids possess many useful health properties, including anti-inflammatory, oestrogenic, enzyme system modulation, antimicrobial, vascular and antitumour activity; however, the antioxidant activity is the most studied one that is attributed to flavonoids and has been found to be responsible for other biological activities in which the prevention of oxidative stress is beneficial [164-166]. Flavonoids also possess anticancer activity, which has been shown to go beyond the antioxidant, free radical-scavenging activity, but may involve mechanisms such as regulation of gene expression in cell proliferation, oncogenes and tumour suppressor genes, induction of cell cycle arrest and apoptosis, modulation of detoxification enzymes activity, stimulation of immune system and regulation of hormone metabolism [165]. The main subclasses of flavonoids are flavones, flavonols, flavanols, anthocyanins, isoflavones, flavanones, chalcones and dihydrochalcones [157,164166]. Other classes include the coumarins, aurones, dihydroflavonols and flavan-3,4-diols.

\section{Rooibos (Aspalathus linearis)}

\subsection{History, distribution of the species and morphology}

Rooibos, Aspalathus linearis (Brum f) Dahlg. (Family Fabaceae; tribe Crotolarieae), is a hardy shrub that grows between 1.5 and $2 \mathrm{~m}$ in height with bright green, needle-shaped leaves and small, yellow flowers [167]. After harvesting, the needle-like leaves and stems can be either bruised and fermented prior to drying or dried immediately [168]. The unfermented product remains green in colour and is referred to as green rooibos. During fermentation, the colour changes from green to red as a result of the oxidation of the constituent polyphenols and the final product is often referred to as red tea or red bush tea. The genus Aspalathus comprises about 278 species and is endemic to South Africa, showing a high degree of polymorphism in terms of morphology, geographical distribution, ecology and phenolic constituents [169]. Rooibos has been consumed by locals for over 300 years, but it was not known outside South Africa until 1904 when Benjamin Ginsberg, a Russian immigrant to South Africa, recognized its potential and started trading with rooibos that he bought from the Khoi descendants and became the first exporter of rooibos. In the 1930s, Dr P.F. Le Fras Nortier, a local doctor and amateur botanist, realized the commercial potential of rooibos and initiated its cultivation in plantations by local farmers (http://www.sarooibos.co.za/content/view/31/79; retrieved on 08/10/2010). By 1999/2000, rooibos production was between 4500 and 6000 metric tonnes with the domestic market absorbing $70-75 \%$ of the annual production. Today, rooibos cultivation has reached a large scale of more than 12,000 metric tonnes, serving both local and increasing international market demand [170].

\subsection{Phytochemical composition}

The herbal beverage made from rooibos is naturally caffeine-free [171,172] and low in tannin when compared to Camellia sinensis teas [173]. The leaf tannin content of rooibos is reported to 
be about $3.2-4.4 \%[174,175]$. Rooibos is unique in its monomeric flavonoid composition, containing two unique compounds, namely aspalathin and aspalalinin. Aspalathin is a C-Clinked dihydrochalcone glucoside [176,177] and aspalalinin is a cyclic dihydrochalcone [178], and both are only isolated from rooibos. Rooibos is also one of the only three known sources of nothofagin, a 3-dehydroxydihydrochalcone glucoside $[179,180]$. The other known sources of nothofagin are the heartwood of Nothofagus fusca [181] and the bark of a Chinese medicinal plant, Schoepfia chinensis [182]. Other flavonoids in rooibos include the C-C-linked $\beta$-Dglucopyranosides such as flavones orientin and iso-orientin [183] as well as vitexin and isovitexin, both flavone analogues of nothofagin [177]. The flavanones, dihydro-orientin and dihydroiso-orientin [184], as well as hemiphlorin [178] have also been isolated from rooibos. Other flavones isolated from rooibos include chrysoeriol, luteolin and luteolin-7-o-glucoside, while the flavonols quercetin, quercetin-3-orobinoside, hyperoside, isoquercitrin and rutin are also present $[177,178,184-187]$. The presence of phenolic acids, lignans and the coumarin, esculentin [177,178,187], as well as monomeric flavan-3-ol, (+)-catechin and oligomeric flavan-3-ol, procyanidin B3 and bis-fisetinidol- $(4 \beta, 6: 4 \beta, 8)$-cathechin $[187,188]$, has also been detected in rooibos. Figure 2 shows the major flavonoids that have been identified from rooibos.<smiles>O=C(CCc1ccc(O)c(O)c1)c1c(O)cc(O)c(C(Cl)(Cl)Cl)c1O</smiles>

Aspalathin<smiles>O=c1cc(-c2ccc(O)c(O)c2)oc2c(Cl)c(O)cc(O)c12</smiles>

Orientin<smiles>O=C1CCc2cc(O)c(O)cc2Oc2cc(O)c(C(F)(Cl)C3CCCCC3)c(O)c21</smiles>

Aspalalinin<smiles>O=c1cc(-c2ccc(O)c(O)c2)oc2cc(O)c(C(Cl)Cl)c(O)c12</smiles>

Iso-orientin<smiles>O=C(CCc1ccc(O)cc1)c1c(O)cc(O)c(Cl)c1O</smiles>

Nothofagin<smiles>O=c1cc(-c2ccc(O)cc2)oc2c(Cl)c(O)cc(O)c12</smiles>

Vitexin<smiles>O=c1cc(-c2ccc(O)c(O)c2)oc2cc(O)cc(O)c12</smiles>

Luteolin<smiles>O=c1cc(-c2ccc(O)cc2)oc2cc(O)c(C(Cl)Cl)c(O)c12</smiles>

Iso-vitexin

Figure 2. Some major flavonoids identified in rooibos (Glc $=C-\beta$-D-glucosyl group)

As a result of fermentation during the processing of rooibos, the content of polyphenols in rooibos is reduced. Studies have found a higher percentage of total polyphenols, flavonoids 
and non-flavonoids in unfermented/green rooibos compared to fermented/red rooibos [189191]. These differences may be attributed to (i) the enzymatic and chemical modifications that occur during fermentation and (ii) the processing methods used $[179,190]$. During fermentation, aspalathin present in unfermented rooibos is extensively oxidized to dihydroiso-orientin. Nothofagin, iso-orientin, isovitexin and vitexin are degraded as well, but to a lesser extent $[179,187,192,193]$. In vitro studies revealed that fermentation and processing also affect the antioxidant activities of rooibos, with results showing that antioxidant activity (measured by different free radical-scavenging assays) decreases with fermentation [190,194-196], an effect attributed to a decreased total polyphenol content with fermentation.

\section{Biological activities and potential of rooibos in oxidative stress-induced conditions}

The attractiveness and use of naturally occurring compounds including those derived from fruits, vegetables, teas, various herbs and spices as potential chemopreventive and chemotherapeutic agents are gaining worldwide appeal. Evidence abounds that rooibos and/or its flavonoids hold great potential not only in the prevention but also in therapy of a wide variety of disease conditions. Since the first report on the biological activity of rooibos, an enormous body of work has revealed that rooibos extracts possess antioxidant, antimutagenic, antiinflammatory, anti-diabetic, hepatoprotective, antimicrobial and, above all, cancer-preventive properties. The following sections will therefore take a detailed look at the various biological and health-promoting effects that have been shown for rooibos.

\subsection{Antioxidant and lipid peroxidation inhibition activities}

Although the controlled production of ROS has important physiological roles especially in energy production, phagocytosis, regulation of cell growth and cellular signalling, a high ROS production not counterbalanced by cellular antioxidant defense may result in oxidative stress. As previously mentioned, oxidative stress has been implicated in the pathogenesis of many disease conditions such as cancer, cardiovascular diseases, atherosclerosis, hypertension, ischaemia/reperfusion injury, diabetes mellitus, neurodegenerative disorders (Alzheimer's and Parkinson's disease), rheumatoid arthritis and ageing. Rooibos is a potent source of unique and beneficial phytochemicals, which are thought to contribute to its health benefits. Several studies have confirmed that rooibos showed antioxidant and lipid peroxidation inhibition activities both in vitro and in vivo. Extracts of fermented and unfermented rooibos as well as rooibos flavonoids showed in vitro antioxidant activity by scavenging free radicals $[190,194-$ 199]. Aqueous extracts of fermented rooibos showed in vitro inhibition of lipid peroxidation in cell membranes using rabbit erythrocyte membrane, rat liver microsome and rat liver homogenates [196,200], while methanolic extracts of fermented and unfermented rooibos inhibited microsomal lipid peroxidation [201]. Rooibos was also shown to scavenge alkyl peroxyl radicals formed during lipid peroxidation [202]. Aqueous and methanolic extracts of rooibos inhibited peroxyl radical-induced DNA strand scission in a dose-dependent manner, 
with the aqueous extract being less effective compared with the methanolic extract [203]. Treatment with fermented rooibos increased the viability of Chinese hamster fibroblast (V79-4) cells following $\mathrm{H}_{2} \mathrm{O}_{2}$-induced oxidative stress by increasing the activity of antioxidant enzymes superoxide dismutase (SOD) and catalase (CAT) [204].

The antioxidant effects shown by rooibos in vitro has been confirmed in many experimental animal model studies. Aqueous rooibos extract administration suppressed age-related accumulation of lipid peroxides in several regions of the rat brain [205]. Gastric intubation of luteolin (a flavonoid found in rooibos, at $10-\mu \mathrm{mol} / \mathrm{kg}$ body weight) given 2 hours prior to $\gamma$ ray irradiation suppressed lipid peroxidation in mice bone marrow and spleen [206]. In a study in vitamin E-deficient rats, dietary supplementation of a freeze-dried hot water extract of rooibos decreased the level of lipid peroxidation in the liver, lung, small intestine and stomach of the animals, although the changes were not significant [207].

In the presence of reactive species, GSH is rapidly oxidized to GSSG and in its turn exported from cells. Intracellular levels of GSH, GSSG or the ratio of GSH:GSSG serve as good indicators of oxidative stress. The ability of rooibos extracts to inhibit lipid peroxidation and modulate antioxidant status in different organs and/or tissues has been widely reported. In 2003, Marnewick et al. [208] reported on the effect that chronic feeding of a $2 \%(w / v)$ aqueous extracts of both fermented and green rooibos had on the modulation of oxidative stress in male Fischer rats. Consumption of the fermented and green rooibos extract for 10 weeks did not have any effect on the antioxidant capacity (measured as ORAC) of the liver; however, both extracts significantly improved the glutathione (GSH) redox status of the liver by reducing the level of oxidized glutathione (GSSG) and thus increasing the GSH:GSSG ratio significantly. Simultaneously, the rooibos extracts also significantly enhanced the activities of the important hepatic phase II drug-metabolizing enzymes, glutathione S-transferase alpha and UDP-glucoronosyl transferase.

Using different models of induced oxidative stress, the effect of rooibos extracts supplementation has been reported widely. Fermented rooibos extract given for 10 weeks increased the antioxidant status of the $\mathrm{CCl}_{4}$-treated rats by increasing $\alpha$-tocopherol and reducing the liver concentrations of coenzyme $Q$ while inhibiting the formation of malondialdehyde [209]. A study by Awoniyi et al. [210] reported that fermented and green rooibos offer a measure of protection against tert-butyl hydroperoxide ( $\mathrm{t}-\mathrm{BHP}$ )-induced oxidative damage in rat sperm by increasing the antioxidant defense mechanism and thereby improving sperm motility and function. The authors concluded that a wide spectrum of polyphenolic compounds present in rooibos are effective as antioxidants; thus, rooibos could offer a therapeutic effect in the treatment of infertility. More recent studies in our laboratory have also reported on the ability of rooibos to inhibit lipid peroxidation and improve the glutathione redox status in the liver of rats. In one of the studies, male Wistar rats were supplemented with fermented rooibos for 10 weeks, while oxidative stress was induced by intraperitoneal injection of t-BHP in the last 2 weeks. Results from this study showed that rooibos supplementation was able to inhibit lipid peroxidation by decreasing the elevation in conjugated dienes and malondialdehyde levels induced by t-BHP. Simultaneously, the fermented rooibos extract also improves the glutathione redox status by increasing the reduced glutathione (GSH) concentration and invariably 
the GSH/GSSG ratio in the plasma and liver of the rats [211]. In another study, lipopolysaccharide (LPS) (Escherichia coli, serotype 0111:B4, $0.5 \mathrm{mg} / \mathrm{kg}$ b.w., i.p.) was used as an oxidative damage inducer in rats pre-fed fermented rooibos for 4 weeks. Results showed that pre-feeding rooibos inhibited plasma and hepatic formation of malondialdehyde (marker of lipid peroxidation) and also restored the impairment in glutathione redox status [212]. These studies showed that rooibos and its constituent polyphenols are effective antioxidants in vivo. Although the mechanisms by which rooibos offers protection in oxidative stress-induced conditions are not fully understood, however, we believed that the potential mechanisms by which this protection is achieved could involve one or more of several different antioxidant properties exhibited by flavonoids in rooibos. Rooibos polyphenols could be scavenging ROS directly by binding lipid peroxides or they may act as sacrificial antioxidants to inhibit the lipid peroxidation cascade. In improving the glutathione redox status, rooibos improved the antioxidant status of the cell. This effect may result from the ability of flavonoids present in rooibos to up-regulate the mRNA expression of $\gamma$-glutamylcysteine synthetase, the ratelimiting enzyme in the biosynthesis of glutathione.

\subsection{Hepatoprotective effects}

Chronic hepatic disease represents one of the foremost health problems worldwide, with liver cirrhosis and drug-induced liver injury accounting for the ninth leading cause of death in the western and developing countries [213]. In vitro and in vivo evidence suggests that free radical damage and oxidative stress contributing to lipid peroxidation is a critical mechanism implicated in the genesis and progression of different chronic liver diseases. It is a well-known fact that the available synthetic drug to treat liver disorders might also cause further damage to the liver [214]. Hence, medicinal plants have become increasingly popular and their use is widespread.

Hepatoprotective effects of rooibos has been reported in a number of studies. Consumption of rooibos protected against liver damage by suppressing the observed increase in plasma activities of aspartate aminotransferase (AST), alanine aminotransferase (ALT), alkaline phosphatase and bilirubin, and resulted in a histological regression of steatosis and cirrhosis in the liver of rats challenged with carbon tetrachloride $(1 \mathrm{~mL} / \mathrm{kg}$, i.p. $)$ twice a week for 10 weeks [215]. Another study from the same laboratory also reported that rooibos supported the regeneration of rat liver after intoxication with carbon tetrachloride, and this protective effect was ascribed to the ability of rooibos to inhibit lipid peroxidation in the liver [216].

In a t-BHP-induced hepatotoxicity model study, fermented rooibos consumption by rats reversed the elevation in serum aminotransferases and lactate dehydrogenase induced by $\mathrm{t}$ BHP [211]. Histologically, the severe hepatic degeneration, hepatocyte vacuolation as well as massive lymphocyte and mononuclear cellular aggregation induced by t-BHP were also reversed. The hepatoprotective effect of rooibos was confirmed in another study by the same group when they reported on the amelioration of lipopolysaccharide-induced acute liver injury by a fermented rooibos extract [212]. Based on the result from these studies, the authors concluded that the hepatoprotective effects shown by fermented rooibos could be ascribed to a stabilizing effect of rooibos phenolics on the plasma membrane of hepatocytes, as well as the 
repair of damaged hepatic tissues probably brought about by the stimulation of hepatocellular protein synthesis and accelerated regeneration of the hepatocytes, thus suggesting that rooibos may be of benefit in the prophylactic management of oxidant-induced liver injuries.

\subsection{Anti-diabetic effects}

Diabetes is one of the most common global diseases and affects approximately 200 million people worldwide $[217,218]$, with the figure forecasted to rise to around 300 million people by 2025 [219]. Long-term effects of diabetes include progressive development of specific complements such as retinopathy, nephropathy and neuropathy. People with diabetes are also at risk for cardiovascular, peripheral vascular and cerebrovascular diseases. All these complications substantially increase the rates of morbidity and mortality associated with the disease and reduce the quality of life of the diabetic individuals. A chronic disease characterized by increased blood sugar, diabetes can result from lack of insulin production and/or resistance to insulin. Insulin resistance alone does not result in the development of type 2 diabetes, and reports have shown that there must be progressive dysfunction of pancreatic islets, which disrupt the secretion of glucagon from the $\alpha$ cells and insulin from $\beta$ cells, leading to uncontrolled hyperglycaemia, for the disease to develop [220].

Experimental evidence suggests the involvement of overproduction of free radicals in the onset of diabetes and diabetic complications, with oxidative stress proposed as a pathogenic mechanism linking insulin resistance with the dysfunction of beta cells and endothelium, impaired glucose tolerance and overt diabetes. $\beta$-Cell dysfunction in the diabetic state may result from a decrease in $\beta$-cell mass, and this has been attributed to oxidative stress-induced apoptosis [221]. The apoptotic state in the $\beta$-cells was reported to be triggered by high glucose concentration (glucotoxicity), possibly due to increased production of ROS. In addition, evidence has shown that $\beta$-cells have very low expression of antioxidant enzymes, making them more susceptible to oxidative damage [221-223]. Both pancreatic $\alpha$-and $\beta$-cells play vital roles in the maintenance of normal glucose homeostasis, and studies has shown that abnormal glucagon secretion is a hallmark of the diabetic state, suggesting that glucose sensing by the $\alpha$-cells is also dysfunctional [224,225]. The effect of oxidative stress on $\alpha$-cells in the diabetic state is less clear; however, evidence has shown that uncoupling protein 2 (UCP 2), a mitochondrial proton carrier protein, is highly expressed in pancreatic $\alpha$-cells [225]. A central role has been suggested for UCP 2 in ROS-mediated injury in the diabetic state, with several reports indicating that UCP 2 is negatively correlated with the level of ROS generation by respiring mitochondria [226]. Some authors have reported that in contrast to $\beta$-cells, islet $\alpha$-cells are resistant to diabetogenic toxins, an observation the authors adduced to the fact that $\alpha$-cells displayed high level of catalase expression and activity [227], suggesting that $\alpha$-cells may be more resistant to ROS damage. Biomarkers of oxidative damage including malondialdehyde, F2-isoprostane, protein carbonyls and advanced glycation end products (AGE) are reported to be elevated in either the plasma, erythrocytes or liver of streptozotocin (STZ)-induced diabetic rats [228-231], as well as in the plasma or urine of diabetic patients [232-234], giving further evidence of ROS contribution to the onset, progression and pathological consequence of diabetes. In addition, the level of cellular non-enzymatic antioxidants such as vitamin E, 
vitamin C and reduced GSH is depleted in different tissues of experimentally induced diabetes $[235,236]$ and in diabetic patients [234,237-239]. The modulation of the antioxidant enzymes network in the diabetic state is another indirect evidence in support of the role of oxidative stress in diabetes and diabetic complications, an effect which has been reported to be highly variable, depending on the model of diabetes used and the tissue type assessed [240].

Several polyphenol-rich plants and/or plant extracts have been used for controlling diabetes [241,242]. Polyphenols may affect glycaemia through different mechanisms, including inhibition of intestinal glucose absorption, increasing glucose transport and metabolism in muscle and/or stimulating insulin secretion [217,219,243,244]. A report by Johnston et al. [245] demonstrated that glucose uptake into cells under sodium-dependent conditions was inhibited by flavonoid glycosides and non-glycosylated polyphenols in polarized Caco- 2 intestinal cells. Under sodium-free conditions, aglycones and non-glycosylated polyphenols inhibited glucose uptake, whereas glycosides inhibited the active transport of glucose [246].

Investigation into the anti-diabetic properties of rooibos in streptozotocin-induced diabetic rats showed that the administration of aqueous and alkaline extracts of rooibos to diabetic rats did not affect markers of diabetic status such as glucose, glycated haemoglobin and fructosamine; however, biochemical markers characterizing hepatotoxic effects in plasma, advanced glycation end products (AGEs) and malondialdehyde in plasma and in different tissues of the diabetic rats were reduced [247]. Previously, an in vitro study by Kinae et al. [248] reported that a freeze-dried extract of fermented rooibos suppressed the formation of glycated albumin, including AGEs in a mixture of D-glucose and human serum albumin. Quercetin, a flavonol found in rooibos in small concentrations, has been shown to mediate the inhibition of the facilitated diffusion of glucose transporter 2 (GLUT2) in Chinese hamster ovary cells [249].

The hypoglycaemic and anti-diabetic activity of aspalathin (major polyphenol of rooibos) in type 2 diabetic model $\mathrm{db} / \mathrm{db}$ mice was demonstrated for the first time in a study by Kawano et al. [250]. In the study, purified aspalathin from a fermented rooibos extract increased dosedependently and significantly the glucose uptake by L6 myotubes at concentrations of 1-100 $\mu \mathrm{M}$, irrespective of insulin absence and also increased insulin secretion from cultured RIN-5F cells at $100 \mu \mathrm{M}$. Dietary aspalathin $(0.1-0.2 \%, \mathrm{~g} / \mathrm{kg}$ diet $)$ suppressed the increase in fasting blood glucose levels for 5 weeks and improved impaired glucose tolerance at 30, 60, 90 and $120 \mathrm{~min}$ in $\mathrm{db} / \mathrm{db}$ mice. The results from this study presented the first evidence of the beneficial effects of aspalathin on glucose homeostasis in type 2 diabetes, through the stimulation of glucose uptake in muscle tissues, and insulin secretion from pancreatic $\beta$-cells.

In another study, a fermented aqueous extract and an aspalathin-enriched unfermented extract of rooibos were reported to lower the elevation in blood glucose observed, in an STZ-induced hyperglycaemic Wistar rat model [251]. The same study also reported that the elevated blood glucose observed in a diet-induced model of type 2 diabetes in vervet monkeys was lowered by a fermented aqueous extract of rooibos.

The hypoglycaemic potential of an aspalathin-enriched green rooibos extract, aspalathin, rutin and an aspalathin-rutin mixture was investigated by Muller et al. [252] in C2C12 myotubules and STZ-induced diabetic rats. Results from the study showed that the enriched green rooibos 
extract induced a dose-response increase in glucose uptake on C2C12 myotubules; aspalathin was effective at 1, 10 and $100 \mu \mathrm{M}$ while rutin was effective at $100 \mu \mathrm{M}$. In STZ-induced diabetic rats, the aspalathin-enriched rooibos extract and the aspalathin-rutin mixture but not the single compounds separately reduced blood glucose concentrations, indicating that the hypoglycaemic effect may be due to synergistic interactions of polyphenols present in rooibos. Using a similar in vitro approach in C2C12 muscle cells, Mazibuko et al. [253] reported that an aspalathin-enriched green rooibos extract and an aqueous extract of fermented rooibos ameliorate palmitate-induced insulin resistance, with both extracts increasing glucose uptake, mitochondrial activity and ATP production. Further studies from the same group revealed that fermented rooibos extract has a potential for preventing obesity by inhibiting adipogenesis in differentiating 3T3-L1 adipocytes [254] and also showed cardioprotective effect in isolated cardiomyocytes derived from diabetic rats, subjected to experimentally-induced oxidative stress and ischaemia [255].

Vascular inflammation induced by high glucose is key in the initiation and progression of arthrosclerosis, a major diabetic complication. In another study investigating the benefit of rooibos in the treatment of diabetic complications, $\mathrm{Ku}$ et al. [256] assess whether aspalathin and nothofagin can suppress vascular inflammation induced by high glucose in human umbilical vein endothelial cells (HUVECs) and mice. Results from the study showed that aspalathin and nothofagin inhibited high glucose-mediated vascular permeability, adhesion of monocytes towards HUVEC and expression of cell adhesion molecules and suppressed ROS formation and nuclear factor-к $\beta(\mathrm{NF}-\mathrm{\kappa} \beta)$ activation in vitro and in vivo.

Although these studies strongly suggest that rooibos and its polyphenols effect their antidiabetic potential through multiple modes of action, some authors have suggested that because rooibos and/or aspalathin are capable of scavenging intracellular reactive oxygen species (ROS), the anti-diabetic potential of rooibos may be due to its antioxidative function, which may be involved in the activation of insulin-stimulated glucose uptake, and hence the modulation of glucose homeostasis [257].

\subsection{Antimutagenic, antitumourigenic and anti-carcinogenic effects}

The increasing mortality and morbidity arising from various cancers worldwide have made the search for an alternative strategy (such as the use of bioactive components from plants) in the prevention and management of cancers very imperative. Results from studies in recent decades have shown that bioactive compounds from plants have important roles in the prevention, and reducing the risks of chronic diseases, including cancer $[258,259]$. The beneficial effects shown by these compounds are attributed, among others, to their antioxidant and free radical-scavenging ability.

Rooibos is a rich and unique source of polyphenols, and the polyphenols present in rooibos being powerful antioxidants may play important roles in the prevention of cancer by reducing damage to DNA in the cell, and modulating the promotion of cancer. Several studies have demonstrated the in vitro antimutagenic properties of both fermented and unfermented rooibos extracts using various test systems. Fermented aqueous rooibos extract $(3.33 \%, \mathrm{w} / \mathrm{v})$ significantly suppressed the number of chromosomal aberrations in Chinese hamster ovary 
cells induced by benzo[a]pyrene (BaP) and mitomycin C (MMC) in the presence or absence of rat liver microsomal enzymes (S9). The clastogen-suppressing effect was obtained when cells were exposed to rooibos before and/or after mutagen treatment [260]. Aqueous extract of rooibos (2-10\% of extract) suppressed oncogenic transformation of mouse fibroblast cells subjected to X-ray-induced transformation in a dose-dependent manner [261]. In another study, the effect of different concentrations of a fermented rooibos extract included in the culture medium, on growth and changes of growth parameters of cultured chick embryonic skeletal muscle cells, was investigated. It was discovered that the rooibos extract significantly inhibited cell proliferation as reflected by decreased DNA, RNA and protein contents in primary cell cultures of fibroblasts and myoblasts, in a dose-dependent manner [262]. The in vitro antimutagenic property of rooibos was further investigated by Marnewick et al. [189]. Both fermented and unfermented rooibos extracts $(5 \%$ and $10 \%, \mathrm{w} / \mathrm{v})$ were significantly effective against 2-acetylaminofluorene (2-AAF) and aflatoxin $\mathrm{B}_{1}\left(\mathrm{AFB}_{1}\right)$-induced mutagenesis in the Salmonella typhimurium mutagenicity assay (tester strain TA98 and TA100) in the presence of metabolic activation with S9. However, poor inhibitory effects against the directacting mutagens, methyl methanesulphonate, cumene hydroperoxide and $\mathrm{H}_{2} \mathrm{O}_{2}$ using tester strain TA102, were observed. Further studies using the same Salmonella assay revealed that fermented rooibos exhibited a higher antimutagenic activity than unfermented rooibos against both $\mathrm{AFB}_{1}$ and 2-AAF, although antimutagenic activity of both rooibos extracts was comparable to that of an extract prepared from Camellia sinensis [263]. Using genetically engineered V79 Chinese hamster fibroblasts that expressed human CYP1A2, N(O)-acetyltransferase (hNAT2*4) and sulphotransferase (hSULT1A1*1), Platt et al. [264] showed that rooibos moderately protects against the genotoxicity of 2-amino-3-methylimidazo(4,5-f)quinoline (IQ) and the protection shown was comparable to that shown by green and black teas. In another study, aqueous extracts of unfermented rooibos inhibited cell proliferation of human oesophageal cancer cells (WHCO5) by affecting energy (ATP) production [265]. The antimutagenic properties of the most prevalent flavonoids in rooibos (aspalathin and nothofagin) and their flavone derivatives were investigated by Snijman et al. [266]. The results showed that aspalathin, nothofagin and their structural flavonoid analogues displayed moderate antimutagenic properties, while luteolin and to some extent chrysoeriol showed activities comparable to those of the green tea flavonoids, EGCG. In the same study, quercetin and isoquercetin exhibited antimutagenic, pro-mutagenic and mutagenic effects in the presence or absence of metabolic activation.

The in vitro antimutagenic potential of rooibos extracts has been substantiated by several animal model experiments. Intraperitoneal injection of fermented rooibos extract $(1 \mathrm{~mL}$ of $0.1 \%, \mathrm{w} / \mathrm{v}) 6 \mathrm{~h}$ prior to MMC treatment reduced the induction of micronucleated reticulocytes (MNRETs) in peripheral blood of ICR male mice [260]. The ex vivo antimutagenic potential of fermented and unfermented rooibos was established in a 10-week rooibos feeding study in male Fischer rats. It was discovered that liver cytosolic fractions from rats consuming fermented and unfermented rooibos protected against $\mathrm{AFB}_{1}$-induced mutagenesis in the Salmonella typhimurium assay with tester strain TA100. However, only liver cytosolic fraction from rats fed the unfermented rooibos showed protection against 2-AAF-induced mutagenesis in the same assay with tester strain TA98 [267]. In addition, the activation potential of hepatic 
microsomal preparations from rats consuming rooibos was evaluated in the study, with rooibos reducing the activation of $\mathrm{AFB}_{1}$, but not that of 2-AAF.

The antitumourigenic activity of rooibos was established in a two-stage mouse skin carcinogenesis assay. Topical application of ethanol/acetone soluble fractions of fermented and unfermented rooibos prior to tumour promotion with 12-O-tetradecanoylphorbol-13-acetate (TPA) on ICR mouse skin initiated with 7,12-dimethylbenz(a)anthracene (DMBA) significantly reduced the number and size of tumours per mouse, as well as delayed tumour development [201]. More recently, a study in female SKH-1 hairless mice showed that the topical application of polyphenol-rich extracts of fermented and unfermented rooibos, prior to ultraviolet Binduced tumour promotion and after DMBA-initiated skin cancer, reduced the number of tumours per mouse by $91.39 \%$ and $75.37 \%$, respectively, and also the tumour volume by $97.28 \%$ and $90.74 \%$, respectively [268]. Another study related to tumour promotion in mouse skin showed that the expression of cyclooxygenase-2 (COX2) in ICR mouse skin by TPA was significantly reduced by a methanolic extract of fermented rooibos $(60,300,600 \mu \mathrm{g}$, topically applied prior to TPA exposure) [269]. A recent study, which monitored the cancer-modulating properties of hot water extracts of fermented and unfermented rooibos in a liver carcinogenesis model against fumonisin $\mathrm{B}_{1}\left(\mathrm{FB}_{1}\right)$ promotion in male Fischer rat using diethylnitrosamine as cancer initiator, showed that unfermented rooibos was more protective against $\mathrm{FB}_{1}$-induced cancer promotion, by significantly reducing the total number and size of pre-neoplastic foci staining positively for the placental form of $\gamma$-glutamyl transferase in the liver, presumably by arresting their growth [270]. A similar study investigated the protective effect of rooibos against methylbenzylnitrosamine-induced oesophageal cancer in male Fischer rats and reported that fermented and unfermented rooibos significantly reduced the number and size of papillomas, with rats drinking unfermented rooibos failing to develop larger papillomas $[265,271]$. Results from these studies suggest that rooibos could be developed as a nutraceutical for the chemoprevention of liver and oesophageal cancer.

\subsection{Anti-inflammatory effects}

Inflammation plays an important role in various diseases, such as rheumatoid arthritis, atherosclerosis and cardiovascular diseases, type 2 diabetes and cancers, which all show a high prevalence globally. Since ancient times, in various cultures worldwide, inflammatory disorders and related diseases have been treated with plants or plant-derived formulations, and the anti-inflammatory activity of several plant extracts and isolated compounds has been demonstrated scientifically [272]. A possible explanation for these anti-inflammatory effects of plant extracts may be found in the interplay between oxidative stress and inflammation. ROS are involved not only in the occurrence of oxidative stress but also in the promotion of inflammatory processes via activation of transcription factors such as NF-K $\beta$ and activator protein (AP)-1, which induce the production of cytokines like TNF- $\alpha[273,274]$.

Scientific studies reporting on the possible anti-inflammatory effects of rooibos and/or its flavonoids are sparse. A study in Japan reported that unfermented rooibos extract $(1.6 \%$, $\mathrm{w} / \mathrm{v}$ ) administration as the only source of drinking fluid for 8 weeks reduced inflammation in dextran sodium sulphate (DSS)-induced colitis rats via an increased antioxidant activity [275]. 
There was a significant increase in serum SOD and urine 8-hydroxy-2' deoxyguanosine levels in rooibos rats compared to the control and the DSS rats. Based on these findings, the authors concluded that rooibos may prevent DNA damage and inflammation by its antioxidative activity in vivo. The anti-inflammatory activity of a rooibos tea extract in DMSO $(0.5 \mathrm{mg} / \mathrm{mL})$ and two of its flavonoids (luteolin and quercetin) was investigated, together with that of other herbal extracts, in a study using a lipopolysaccharide-stimulated macrophage model. The study results revealed that incubation with a rooibos extract $(0.5 \mathrm{mg} / \mathrm{mL})$ significantly reduced the secretion of the pro-inflammatory cytokine, IL-6, by at least $25 \%$ and marginally reduced the expression of inducible nitric oxide synthase (iNOS). However, the secretion of the antiinflammatory cytokine, IL-10, was also reduced [272]. In the same study, rooibos flavonoids luteolin and quercetin at concentrations of 50 and $100 \mathrm{nM}$ reduced the secretion of IL- 6 and TNF- $\alpha$, while also inhibiting the expression of cyclooxygenase 2 (COX-2) and iNOS.

More recent studies in our laboratory has shown that fermented rooibos extract shows antiinflammatory effect by suppressing lipopolysaccharide-triggered inflammatory response. In the liver, fermented rooibos consumption suppressed the elevation in pro-inflammatory cytokines, TNF- $\alpha$ and IL-6 [212], while increasing the plasma level of anti-inflammatory cytokine, IL-10 [276]. Lee and Bae [277] investigated the anti-inflammatory effects and underlying mechanisms of aspalathin and nothofagin against LPS-mediated vascular inflammatory responses in HUVECs and mice. Results from this study showed that both compounds possess anti-inflammatory functions in vitro by inhibiting LPS-induced barrier disruption, expression of cell adhesion molecules (CAMs) and adhesion/transendothelial migration of neutrophils to endothelial cells, as well as hyper-permeability and leukocyte migration in vivo. Furthermore, treatment with each compound ameliorated LPS-induced lethal endotoxaemia and suppressed the production of TNF- $\alpha$, IL- 6 and activation of nuclear factor- $\mathrm{k} \beta$ (NF$\mathrm{\kappa} \beta$ ) or extracellular regulated kinases (ERK) 1/2. These studies demonstrated that rooibos and its major flavonoids may contribute to the reduction of inflammation and be preventive against related diseases.

\subsection{Human studies}

Reports examining the health benefits of rooibos in humans have been scarce and limited. However, various health-promoting effects, including antioxidant and oxidative stress modulation, inhibition of postprandial oxidative stress, inhibition of angiotensin-converting enzymes (ACEs), lipid profile modulation, promotion of hair growth and anti-wrinkle activity, among others, have been reported for rooibos in humans.

The first human study with rooibos was conducted by Hesseling et al. [278], when they studied the effects of rooibos compared with black tea and water on iron absorption in 30 healthy young men. The study revealed that rooibos consumption $(200 \mathrm{~mL}$ for 14 days) did not have a deleterious effect on the iron status parameters, such as haemoglobin, ferritin, transferrin, serum iron and iron-binding capacity, compared with the control group taking water. A more recent parallel intervention study, involving 175 primary school children in South Africa, revealed that the consumption of $200-\mathrm{mL}$ servings of rooibos twice daily for 16 weeks did not 
have any adverse effects on the iron status parameters including serum ferritin, transferrin, the total iron-binding capacity and the transferrin saturation [279].

A study to test the potential antihistaminic effects of rooibos was conducted in seven patients diagnosed with either asthma or hay fever. Ingestion of fermented rooibos or topical application of a rooibos poultice did not produce any anti-allergenic activities [280]. The dermatological potential of rooibos was demonstrated in a study that revealed the consumption of a diluted infusion of rooibos at least once a week is beneficial to patients with dermatological diseases. In this study, rooibos consumption decreased the incidence of recurrent Herpes simplex and human papilloma virus infection, while patients with atopic dermatitis were successfully treated, resulting in a decrease in itching sensation. In addition, rooibos consumption inhibited the infiltration of neutrophils associated with Behcet's disease, Psoriasis vulgaris and Acne pustulosa [281]. The anti-wrinkle activity of rooibos was demonstrated in a recent study, when a commercial extract of a rooibos blend with Camelia sinensis extract was topically applied to female skin. Results obtained from the study indicated that the extract reduced skin wrinkles by $10 \%$; however, no effect was shown on skin smoothness, roughness and scaliness [282]. Also, Glynn [283] demonstrated that a blend of botanical extracts containing unfermented rooibos, when topically applied to male, promoted hair growth by increasing hair density, number of anagen follicles and hair growth rate.

Sauter [284] investigated the effect of an aspalathin-enriched extract of unfermented rooibos (15\% aspalathin) on the plasma antioxidant status of 20 subjects who were given an oral dose ( $250 \mathrm{mg} /$ tablet) twice daily for 14 days with diet restrictions to ensure low flavonoid intake during the study period. Rooibos consumption did not show any effect on the antioxidant status biomarkers monitored, except a slight decrease in the antioxidant status when the xanthine/xanthine oxidase assay was used. In another study, the effect of unfermented rooibos consumption on the antioxidant status of workers who were occupationally exposed to lead was investigated in a randomized placebo-controlled 8-week intervention trial. The study monitored the indices of lead exposure (blood lead (PbB), erythrocyte porphyrins (EPs) and delta-aminolevunilic acid dehydratase (ALAD)) and antioxidant status markers (SOD, GSH and MDA) in the erythrocytes and plasma. Rooibos consumption did not have any effect on the mean blood lead and erythrocyte porphyrin levels (lead exposure status), but there was a modulation of antioxidant status of the lead-exposed workers as shown by the decreased MDA levels and increased SOD activity and GSH levels in the plasma and erythrocytes of these factory workers [285]. More recently, a study by Francisco [286] showed that fermented rooibos consumption modulated postprandial glycaemia, lipaemia and oxidative stress in healthy subjects after an intake of a standardized fat meal. Consumption of rooibos by the subjects improved their redox status by increasing the total GSH and significantly lowering the level of conjugated dienes and TBARS after 6 hours. Further, the levels of total cholesterol, LDL cholesterol and triacylglycerol as well as high sensitive C-reactive proteins (hs-CRP) were all decreased in the same study. Guerreiro et al. [287] revealed that the consumption of a rooibos infusion with added glucose $(25 \mathrm{~g})$ did not change the glycaemic response when compared to the reference solution (water with $25 \mathrm{~g}$ of glucose) after 2 hours in a Caucasian population of young male and female adults aged 17-24 years, showing that rooibos is a healthy beverage for obese and diabetic patients. An acute, cross-over design intervention study involving 15 healthy volunteers consuming $500 \mathrm{~mL}$ of either water or fermented or unfermented rooibos 
showed that the plasma antioxidant capacity using the TRAP assay increased significantly with both rooibos extracts, reaching a peak 1 hour post consumption. No change in triacylglycerol, cholesterol or uric acid levels was observed with any of the treatments, while a transitory increase in glycaemia observed at 30 minutes was linked to a glucose upload [288]. Marnewick et al. [289] showed that the consumption of six cups of fermented rooibos herbal tea for 6 weeks improved the blood-lipid profile and reduced oxidative stress by decreasing lipid peroxidation and improving the redox status (GSH:GSSG) of adults at risk of CVDs. This study provided the first clinical evidence in humans of the ability of rooibos to modulate oxidative stress in adults at risk for developing heart disease.

A recent randomized, three-phase cross-over study investigated the effect of green tea, black tea and rooibos on the activity of the angiotensin-converting enzyme (ACE) and nitric oxide (NO) level in healthy volunteers. Study subjects received a single oral dose of $400 \mathrm{~mL}$ green tea, black tea or rooibos, with the activity of ACE and NO concentration measured at $0,30,60$ and 180 minutes. The oral intake of a single dose $(400 \mathrm{~mL})$ of rooibos significantly inhibited ACE activity after 30 and 60 minutes, while no significant modulation was seen for green and black teas. When subjects were divided into subgroups according to ACE genotype, those with genotype II and ID showed significant inhibition of ACE activity after intake of rooibos. Rooibos consumption did not have any effect on NO concentration, blood pressure and heart rate [290]. The results of this study are highly significant, since ACE inhibitors are the first-line treatment of hypertension and thus common drugs used for cardiovascular diseases, suggesting that rooibos may have antihypertensive and cardiovascular effects through the inhibition of ACE activity.

\subsection{Adverse reactions and/or toxicity}

Although there is no evidence of any toxicological study that have been conducted for rooibos, however, a number of studies have addressed aspects of safety and toxicity. A widely used measure of safety of medicinal and plant extracts in literature is to determine their effect on serum levels of liver and kidney function markers. Increased serum levels of alanine aminotransferase (ALT), aspartate aminotransferase (AST), alkaline phosphatase (ALP) and lactate dehydrogenase (LDH) are used as surrogate markers for hepatic injury. Animal studies from our laboratory and elsewhere have shown that the consumption of unfermented and fermented rooibos as the sole source of drinking fluid over different lengths of time did not cause any adverse effect regarding body weight, liver weight or liver and kidney parameters including serum transaminases, alkaline phosphatase, creatinine, total and unconjugated bilirubin, total protein, total cholesterol or iron status [208,211,212,215,216,247]. Results from the first human intervention study also demonstrated the first scientific proof for human safety of rooibos consumption, as none of the participants reported any adverse effect and the clinical pathology results (ALT, AST, GGT, ALP, LDH, creatinine, bilirubin, glucose and protein) were all within the reference range [289]. The observations from these studies become all the more important, especially with recent cases of possible adverse hepatic effects of rooibos. Sinisalo et al. [291] reported a case of a 42-year-old patient diagnosed with a low-grade B-cell malignancy, Waldenstrom's macroglobulinaemia, 6 years earlier, who temporarily experienced elevated liver enzymes after consuming relatively large amounts of rooibos. The study reaffirms the 
excellent safety record of rooibos and concluded that the contamination of the rooibos herbal tea by some hepatotoxic compound, genetic predisposition and/or diseased state of the patient to react adversely to one of the many bioactive components in rooibos may be responsible for the effect. A very recent study also reported a case of acute hepatitis and liver failure associated with daily ingestion of rooibos and buchu herbal tea in a 52-year-old man with a history of hyperlipidaemia and stage III chronic kidney disease secondary to IgA nephropathy [292]. These two reports underlined the fact that further study still needs to be done on the safety of rooibos consumption in humans despite the excellent safety record of the tea to date, and also draw attention to the health status of the individual being very important when considering supplementation with dietary antioxidants.

\section{Conclusion and future research directions}

The attractiveness and use of naturally occurring compounds including those derived from fruits, vegetables and herbs as potential chemopreventive and chemotherapeutic agents have become a fascinating strategy, and from the various studies reviewed here, it is evident that rooibos and/or its polyphenols hold great potential not only in the prevention but also in therapy of a wide variety of oxidative stress-induced conditions. Since the first report on the biological activity of rooibos, an enormous body of work has revealed that rooibos extracts possess antioxidant, antimutagenic, anti-inflammatory, anti-diabetic, antimicrobial and, above all, cancer-preventive properties. However, most of the studies have been done in vitro, with ex vivo, in vivo and human trials still limited. This review strongly advocates a shift in focus from in vitro studies to animal and human studies, with future research aimed at defining the actual magnitude of health benefits, establishing a safe range of rooibos tea consumption associated with these benefits (if toxicity is discovered) and elucidating the mechanisms of action in order to predict its efficacy. In addition, definitive conclusions concerning the health benefits of rooibos consumption must come from well-designed observational epidemiological studies and clinical intervention trials. For rooibos and/or its flavonoids to have beneficial effects in vivo, they have to be absorbed and metabolized in such a way that they can reach and target specific sites. Therefore, more studies are needed to focus on rooibos bioavailability, as well as dose-response effects and pharmacokinetic profiling of the hypothetic active metabolites. Studies analysing the effect of rooibos extract in order to follow the synergistic bioactivity of the different flavonoids present in rooibos are also necessary.

\section{Acknowledgements}

Olawale Ajuwon is supported by the postdoctoral research fellowships from the Claude Leon Foundation and the South African National Research Foundation. The authors acknowledge support from the University of Cape Town and the Cape Peninsula University of Technology, South Africa. 


\section{Author details}

Olawale R. Ajuwon ${ }^{1 *}$, Jeanine L. Marnewick ${ }^{2}$ and Lester M. Davids ${ }^{1}$

*Address all correspondence to: Olawale.Ajuwon@uct.ac.za

1 Redox Laboratory, Department of Human Biology, Faculty of Health Sciences, University of Cape Town, Observatory 7925, Cape Town, South Africa

2 Oxidative Stress Research Centre, Institute of Biomedical and Microbial Biotechnology, Cape Peninsula University of Technology, Bellville, South Africa

\section{References}

[1] Freeman, B.A., Campo, J.D. 1982. Biology of disease: free radicals and tissue injury. Laboratory Investigation, 47: 412-426.

[2] Halliwell, B. 2005. Free radicals and other reactive species in disease. Encyclopedia of Life Sciences (pp. 7): Wiley Online Library.

[3] Halliwell, B., Gutteridge, J.M.C. 2007. Free radicals in biology and medicine. Fourth Edition. Clarendon Press, Oxford, UK.

[4] Droge, W. 2002. Free radicals in the physiological control of cell function. Physiological Reviews, 82: 47-95.

[5] Valko, M., Leibfritz, D., Moncol, J., Cronin, M.T.D., Mazur, M., Telser, J. 2007. Free radicals and antioxidants in normal physiological functions and human disease. International Journal of Biochemistry \& Cell Biology, 39: 44-84.

[6] Small, D.M., Coombes, J.S., Bennett, N., Johnson, D.W., Gobe, G.C. 2012. Oxidative stress, anti-oxidant therapies and chronic kidney disease. Nephrology, 17: 311-321.

[7] Valko, M., Rhodes, C., Moncol, J., Izakovic, M., Mazur, M. 2006. Free radicals, metals and antioxidants in oxidative stress-induced cancer. Chemico-Biological Interactions, 160: $1-40$.

[8] Valko, M., Izakovic, M., Mazur, M., Rhodes, C.J., Telser, J. 2004. Role of oxygen radicals in DNA damage and cancer incidence. Molecular and Cellular Biochemistry, 266: 37-56.

[9] Murphy, M.P. 2009. How mitochondria produce reactive oxygen species. Biochemical Journal, 417: 1-13.

[10] Finkel, T. 2012. Signal transduction by mitochondrial oxidants. Journal of Biological Chemistry, 287: 4434-4440. 
[11] Liu, Y., Fiskum, G., Schubert, D. 2002. Generation of reactive oxygen species by the mitochondrial electron transport chain. Journal of Neurochemistry, 80: 780-787.

[12] Kalyanaraman, B. 2013. Teaching the basics of redox biology to medical and graduate students: oxidants, antioxidants and disease mechanisms. Redox Biology, 1: 244-257.

[13] Ott, M., Gogvadze, V., Orrenius, S., Zhivotovsky, B. 2007. Mitochondria, oxidative stress and cell death. Apoptosis, 12: 913-922.

[14] Lugrin, J., Rosenblatt-Velin, N., Parapanov, R., Liaudet, L. 2014. The role of oxidative stress during inflammatory processes. Biological Chemistry, 395: 203-230.

[15] Michiels, C., Raes, M., Toussaint, O., Remacle, J. 1994. Importance of Se-glutathione peroxidase, catalase, and $\mathrm{Cu} / \mathrm{Zn}-\mathrm{SOD}$ for cell survival against oxidative stress. Free Radical Biology and Medicine, 17: 235-248.

[16] Jomova, K., Jenisova, Z., Feszterova, M., Baros, S., Liska, J., Hudecova, D., Rhodes, C.J., Valko, M. 2011. Arsenic: toxicity, oxidative stress and human disease. Journal of Applied Toxicology, 31: 95-107.

[17] Palmer, R., Rees, D.D., Ashton, D.S., Moncada, S. 1988. L-arginine is the physiological precursor for the formation of nitric oxide in endothelium-dependent relaxation. Biochemical and Biophysical Research Communications, 153: 1251-1256.

[18] Bryan, N.S., Bian, K., Murad, F. 2009. Discovery of the nitric oxide signaling pathway and targets for drug development. Frontiers in Bioscience, 14: 1-18.

[19] Nathan, C. 1992. Nitric oxide as a secretory product of mammalian cells. FASEB Journal, 6: 3051-3064.

[20] Geller, D.A., Billiar, T.R. 1998. Molecular biology of nitric oxide synthases. Cancer and Metastasis Reviews, 17: 7-23.

[21] White, P.J., Charbonneau, A., Cooney, G.J., Marette, A. 2010. Nitrosative modifications of protein and lipid signaling molecules by reactive nitrogen species. American Journal of Physiology, Endocrinology and Metabolism, 299: E868-E878.

[22] Carr, A.C., McCall, M.R., Frei, B. 2000. Oxidation of LDL by myeloperoxidase and reactive nitrogen species reaction pathways and antioxidant protection. Arteriosclerosis, Thrombosis, and Vascular Biology, 20: 1716-1723.

[23] Eiserich, J.P., Hristova, M., Cross, C.E., Jones, A.D., Freeman, B.A., Halliwell, B., van der Vliet, A. 1998. Formation of nitric oxide-derived inflammatory oxidants by myeloperoxidase in neutrophils. Nature, 391: 393-397.

[24] Sampson, J.B., Ye, Y.Z., Rosen, H., Beckman, J.S. 1998. Myeloperoxidase and horseradish peroxidase catalyze tyrosine nitration in proteins from nitrite and hydrogen peroxide. Archives of Biochemistry and Biophysics, 356: 207-213. 
[25] Denicola, A., Freeman, B.A., Trujillo, M., Radi, R. 1996. Peroxynitrite reaction with carbon dioxide/bicarbonate: kinetics and influence on peroxynitrite-mediated oxidations. Archives of Biochemistry and Biophysics, 333: 49-58.

[26] Lang Jr, J.D., Chumley, P., Eiserich, J.P., Estevez, A., Bamberg, T., Adhami, A., Crow, J., Freeman, B.A. 2000. Hypercapnia induces injury to alveolar epithelial cells via a nitric oxide dependent pathway. American Journal of Physiology, 279: L994-L1002.

[27] Bartesaghi, S., Wenzel, J., Trujillo, M., L pez, M., Joseph, J., Kalyanaraman, B., Radi, R. 2010. Lipid peroxyl radicals mediate tyrosine dimerization and nitration in membranes. Chemical Research in Toxicology, 23: 821-835.

[28] Phaniendra, A., Jestadi, D.B., Periyasamy, L. 2015. Free radicals: properties, sources, targets and their implication in various diseases. Indian Journal of Clinical Biochemistry, 30: 11-26.

[29] Ye, Z.W., Zhang, J., Townsend, D.M., Tew, K.D. 2015. Oxidative stress, redox regulation and diseases of cellular differentiation. Biochimica et Biophysica Acta, 1850: $1607-1621$.

[30] Prutz, W.A. 1996. Hypochlorous acid interactions with thiols, nucleotides, DNA, and other biological substrates. Archives of Biochemistry and Biophysics, 332: 110-120.

[31] Giles, G.I., Jacob, C. 2002. Reactive sulfur species: an emerging concept in oxidative stress. Biological Chemistry, 383: 375-388.

[32] Gruhlke, M.C.H., Slusarenko, A.J. 2012. The biology of reactive sulfur species. Plant Physiology and Biochemistry, 59: 98-107.

[33] Pourova, J., Kottova, M., Voprsalova, M., Pour, M. 2010. Reactive oxygen and nitrogen species in normal physiological processes. Acta Physiologica, 198: 15-35.

[34] Brunelle, J.K., Bell, E.L., Quesada, N.M., Vercauteren, K., Tiranti, V., Zeviani, M., Scarpulla, R.C., Chandel, N.S. 2005. Oxygen sensing requires mitochondrial ROS but not oxidative phosphorylation. Cell Metabolism, 1: 409-414.

[35] Guzy, R.D., Hoyos, B., Robin, E., Chen, H., Liu, L., Mansfield, K.D., Simon, M.C., Hammerling, U., Schumacker, P.T. 2005. Mitochondrial complex III is required for hypoxia-induced ROS production and cellular oxygen sensing. Cell Metabolism, 1: 401-408.

[36] Mansfield, K.D., Guzy, R.D., Pan, Y., Young, R.M., Cash, T.P., Schumacker, P.T., Simon, M.C. 2005. Mitochondrial dysfunction resulting from loss of cytochrome c impairs cellular oxygen sensing and hypoxic HIF- $\alpha$ activation. Cell metabolism, 1: 393399.

[37] Semenza, G.L., Jiang, B.H., Leung, S.W., Passantino, R., Concordet, J.P., Maire, P., Giallongo, A. 1996. Hypoxia response elements in the aldolase A, enolase 1, and lac- 
tate dehydrogenase A gene promoters contain essential binding sites for hypoxia-inducible factor 1. Journal of Biological Chemistry, 271: 32,529-32,537.

[38] Kim, J., Tchernyshyov, I., Semenza, G.L., Dang, C.V. 2006. HIF-1-mediated expression of pyruvate dehydrogenase kinase: a metabolic switch required for cellular adaptation to hypoxia. Cell Metabolism, 3: 177-185.

[39] Fukuda, R., Zhang, H., Kim, J., Shimoda, L., Dang, C.V., Semenza, G.L. 2007. HIF-1 regulates cytochrome oxidase subunits to optimize efficiency of respiration in hypoxic cells. Cell, 129: 111-122.

[40] Chan, S.Y., Zhang, Y.Y., Hemann, C., Mahoney, C.E., Zweier, J.L., Loscalzo, J. 2009. MicroRNA-210 controls mitochondrial metabolism during hypoxia by repressing the ironsulfur cluster assembly proteins ISCU1/2. Cell Metabolism, 10: 273-284.

[41] Keisari, Y., Braun, L., Flescher, E., 1983. The oxidative burst and related phenomena in mouse macrophages elicited by different sterile inflammatory stimuli. Immunobiology, 165: 78-89.

[42] West, A.P., Brodsky, I.E., Rahner, C., Woo, D.K., Erdjument-Bromage, H., Tempst, P., Walsh, M.C., Choi, Y., Shadel, G.S., Ghosh, S. 2011. TLR signalling augments macrophage bactericidal activity through mitochondrial ROS. Nature, 472: 476-480.

[43] Nakahira, K., Haspel, J.A., Rathinam, V.A.K., Lee, S.J., Dolinay, T., Lam, H.C., Englert, J.A., Rabinovitch, M., Cernadas, M., Kim, H.P. 2011. Autophagy proteins regulate innate immune responses by inhibiting the release of mitochondrial DNA mediated by the NALP3 inflammasome. Nature Immunology, 12: 222-230.

[44] Zhou, R., Yazdi, A.S., Menu, P., Tschopp, J. 2011. A role for mitochondria in NLRP3 inflammasome activation. Nature, 469: 221-225.

[45] Bulua, A.C., Simon, A., Maddipati, R., Pelletier, M., Park, H., Kim, K.Y., Sack, M.N., Kastner, D.L., Siegel, R.M. 2011. Mitochondrial reactive oxygen species promote production of proinflammatory cytokines and are elevated in TNFR1-associated periodic syndrome (TRAPS). Journal of Experimental Medicine, 208: 519-533.

[46] Scherz-Shouval, R., Shvets, E., Fass, E., Shorer, H., Gil, L., Elazar, Z. 2007. Reactive oxygen species are essential for autophagy and specifically regulate the activity of Atg4. EMBO Journal, 26: 1749-1760.

[47] Scherz-Shouval, R., Elazar, Z. 2011. Regulation of autophagy by ROS: physiology and pathology. Trends in Biochemical Sciences, 36: 30-38.

[48] Dalle-Donne, I., Rossi, R., Colombo, R., Giustarini, D., Milzani, A. 2006. Biomarkers of oxidative damage in human disease. Clinical Chemistry, 52: 601-623.

[49] Dalle-Donne, I., Giustarini, D., Colombo, R., Rossi, R., Milzani, A. 2003. Protein carbonylation in human diseases. Trends in Molecular Medicine, 9: 169-176. 
[50] Klaunig, J.E., Kamendulis, L.M., Hocevar, B.A. 2010. Oxidative stress and oxidative damage in carcinogenesis. Toxicologic Pathology, 38: 96-109.

[51] Uchida, K. 2003. 4-Hydroxy-2-nonenal: a product and mediator of oxidative stress. Progress in Lipid Research, 42(4): 318-343.

[52] Carini, M., Aldini, G., Facino, R.M. 2004. Mass spectrometry for detection of 4-hydroxy-trans2-nonenal (HNE) adducts with peptides and proteins. Mass Spectrometry Reviews, 23: 281-305.

[53] Mangialasche, F., Polidori, M.C., Monastero, R., Ercolani, S., Camarda, C., Cecchetti, R., Mecocci, P. 2009. Biomarkers of oxidative and nitrosative damage in Alzheimer's disease and mild cognitive impairment. Ageing Research Reviews, 8: 285-305.

[54] Vignini, A. 2011. Stroke and oxidative stress. Oxidative Stress and Free Radical Damage in Neurology, 137-152.

[55] Roberts, L.J., Morrow, J. 2002. Products of the isoprostane pathway: unique bioactive compounds and markers of lipid peroxidation. Cellular and Molecular Life Sciences, 59: 808-820.

[56] Cracowski, J.L., Durand, T., Bessard, G. 2002. Isoprostanes as a biomarker of lipid peroxidation in humans: physiology, pharmacology and clinical implications. Trends in Pharmacological Sciences, 23: 360-366.

[57] Song, W.L., Lawson, J.A., Reilly, D., Rokach, J., Chang, C.T., Giasson, B., FitzGerald, G.A. 2008. Neurofurans, novel indices of oxidant stress derived from docosahexaenoic acid. Journal of Biological Chemistry, 283: 6-16.

[58] Halliwell, B., Lee, C.Y.J. 2010. Using isoprostanes as biomarkers of oxidative stress: some rarely considered issues. Antioxidants \& Redox Signaling, 13; 145-156.

[59] Niki, E. 2010. Free radicals and lipid peroxidation. Free Radical Biology in Digestive Diseases, 29: 1-11.

[60] Stadtman, E.R. 1992. Protein oxidation and aging. Science, 257: 1220-1224

[61] Pandey, K.B., Rizvi, S.I. 2010. Resveratrol may protect plasma proteins from oxidation under conditions of oxidative stress in vitro. Journal of the Brazilian Chemical Society, 21: 909-913.

[62] Pandey, K.B., Rizvi, S.I. 2011. Biomarkers of oxidative stress in red blood cells. Biomedical Papers, 155: 131-136.

[63] Butterfield, D.A., Dalle-Donne, I. 2014. Redox proteomics: from protein modifications to cellular dysfunction and disease. Mass Spectrometry Reviews, 33: 1-6.

[64] Poole, L.B. 2015. The basics of thiols and cysteines in redox biology and chemistry. Free Radical Biology and Medicine, 80: 148-157. 
[65] Winterbourn, C.C., Hampton, M.B. 2008. Thiol chemistry and specificity in redox signaling. Free Radical Biology and Medicine, 45: 549-561.

[66] Higdon, A., Diers, A.R., Oh, J.Y., Landar, A., Darley-Usmar, V.M. 2012. Cell signalling by reactive lipid species: new concepts and molecular mechanisms. Biochemical Journal, 442: 453-464.

[67] Winther, J.R., Thorpe, C. 2014. Quantification of thiols and disulfides. Biochimica et Biophysica Acta, 1840: 838-846.

[68] Halliwell, B., Whiteman, M. 2004. Measuring reactive species and oxidative damage in vivo and in cell culture: how should you do it and what do the results mean? British Journal of Pharmacology, 142: 231-255.

[69] Wiseman, H., Halliwell, B. 1996. Damage to DNA by reactive oxygen and nitrogen species: role in inflammatory disease and progression to cancer. Biochemical Journal, 313: 17-29.

[70] Dunlop, R.A., Brunk, U.T., Rodgers, K.J. 2009. Oxidized proteins: mechanisms of removal and consequences of accumulation. IUBMB Life, 61: 522-527.

[71] Seifert, U., Bialy, L.P., Ebstein, F., Bech-Otschir, D., Voigt, A., Schröter, F., Prozorovsky, T., Lange, N., Steffen, J., Rieger, M. 2010. Immunoproteasomes preserve protein homeostasis upon interferon-induced oxidative stress. Cell, 142: 613-624.

[72] Avery, S. 2011. Molecular targets of oxidative stress. Biochemical Journal, 434: 201210.

[73] Cecarini, V., Gee, J., Fioretti, E., Amici, M., Angeletti, M., Eleuteri, A.M., \& Keller, J.N. 2007. Protein oxidation and cellular homeostasis: emphasis on metabolism. Biochimica et Biophysica Acta, 1773: 93-104.

[74] Campioni, S., Mannini, B., Zampagni, M., Pensalfini, A., Parrini, C., Evangelisti, E., Relini, A., Stefani, M., Dobson, C.M., Cecchi, C. 2010. A causative link between the structure of aberrant protein oligomers and their toxicity. Nature Chemical Biology, 6: 140-147.

[75] Dizdaroglu, M., Jaruga, P., Birincioglu, M., Rodriguez, H. 2002. Free radical-induced damage to DNA: mechanisms and measurement. Free Radical Biology and Medicine, 32: 1102-1115.

[76] Sander, M., Cadet, J., Casciano, D.A., Galloway, S.M., Marnett, L.J., Novak, R.F., Pettit, S.D., Prestoa, R.J., Skare, J.A., Williams, G.M. 2005. Proceedings of a workshop on DNA adducts: biological significance and applications to risk assessment. Toxicology and Applied Pharmacology, 208: 1-20.

[77] Hoeijmakers, J.H.J. 2009. DNA damage, aging, and cancer. New England Journal of Medicine, 361: 1475-1485. 
[78] Fraga, C.G., Shigenaga, M.K., Park, J.W., Degan, P., Ames, B.N. 1990. Oxidative damage to DNA during aging: 8-hydroxy-2'-deoxyguanosine in rat organ DNA and urine. Proceedings of the National Academy of Sciences, 87: 4533-4537.

[79] Lu, A.L., Li, X., Gu, Y., Wright, P.M., Chang, D.Y. 2001. Repair of oxidative DNA damage. Cell Biochemistry and Biophysics, 35; 141-170.

[80] Guyton, K., Kensler, T. 1993. Oxidative mechanisms in carcinogenesis. British Medical Bulletin, 49: 523-544.

[81] Barber, D.A., Harris, S.R. 1994. Oxygen free radicals and antioxidants: a review. American Pharmacy, NS34: 26-35.

[82] Marnett, L.J. 2000. Oxyradicals and DNA damage. Carcinogenesis, 21: 361-370.

[83] Cooke, J.P. 2003. NO and angiogenesis. Atherosclerosis Supplements, 4: 53-60.

[84] Klaunig, J.E., Kamendulis, L.M. 2004. The role of oxidative stress in carcinogenesis. Annual Review of Pharmacology and Toxicology, 44: 239-267.

[85] Halliwell, B. 2002. Effect of diet on cancer development: is oxidative DNA damage a biomarker. Free Radical Biology and Medicine, 32: 968-974.

[86] Kawanishi, S., Hiraku, Y. 2006. Oxidative and nitrative DNA damage as biomarker for carcinogenesis with special reference to inflammation. Antioxidants and Redox Signaling 8: 1047-1058.

[87] Kozekov, I.D., Nechev, L.V., Moseley, M.S., Harris, C.M., Rizzo, C.J., Stone, M.P., Harris, T.M. 2003. DNA interchain cross-links formed by acrolein and crotonaldehyde. Journal of the American Chemical Society, 125: 50-61.

[88] Liu, X., Lovell, M.A., Lynn, B.C. 2006. Detection and quantification of endogenous cyclic DNA adducts derived from trans-4-hydroxy-2-nonenal in human brain tissue by isotope dilution capillary liquid chromatography nano-electrospray tandem mass spectrometry. Chemical Research in Toxicology, 19: 710-718.

[89] Lovell, M.A., Markesbery, W.R. 2007. Oxidative DNA damage in mild cognitive impairment and late-stage Alzheimer's disease. Nucleic Acids Research, 35: 7497-7504.

[90] Guetens, G., Boeck, G.D., Highley, M., van Oosterom, A.T., de Bruijn, E.A. 2002. Oxidative DNA damage: biological significance and methods of analysis. Critical Reviews in Clinical Laboratory Sciences, 39: 331-457.

[91] Mateos, R., Bravo, L. 2007. Chromatographic and electrophoretic methods for the analysis of biomarkers of oxidative damage to macromolecules (DNA, lipids, and proteins). Journal of Separation Science, 30: 175-191.

[92] Kuo, H.W., Chou, S.Y., Hu, T.W., Wu, F.Y., Chen, D.J. 2007. Urinary 8-hydroxy-2'deoxyguanosine $(8-\mathrm{OHdG})$ and genetic polymorphisms in breast cancer patients. Mutation Research, 631: 62-68. 
[93] Rasanen, J., Sihvo, E., Ahotupa, M., Färkkilä, M., Salo, J. 2007. The expression of 8hydroxydeoxyguanosine in oesophageal tissues and tumors. European Journal of Surgical Oncology, 33(10), 1164-1168.

[94] Chang, D., Wang, F., Zhao, Y.S., Pan, H.Z. 2008. Evaluation of oxidative stress in colorectal cancer patients. Biomedical and Environmental Sciences, 21: 286-289.

[95] Yang, Y., Tian, Y., Yan, C., Jin, X., Tang, J., Shen, X. 2009. Determinants of urinary 8hydroxy-2'-deoxyguanosine in Chinese children with acute leukemia. Environmental Toxicology, 24: 446-452.

[96] Valavanidis, A., Vlachogianni, T., Fiotakis, C. 2009. 8-hydroxy-2'-deoxyguanosine (8$\mathrm{OHdG}$ ): a critical biomarker of oxidative stress and carcinogenesis. Journal of Environmental Science and Health Part C, 27: 120-139.

[97] Agha-Hosseini, F., Mirzaii-Dizgah, I., Farmanbar, N., Abdollahi, M. 2012. Oxidative stress status and DNA damage in saliva of human subjects with oral lichen planus and oral squamous cell carcinoma. Journal of Oral Pathology and Medicine, 41: 736740 .

[98] Gonenç, A., Hac şevki, A., Aslan, S., Torun, M., Şimşek, B. 2012. Increased oxidative DNA damage and impaired antioxidant defense system in patients with gastrointestinal cancer. European Journal of Internal Medicine, 23: 350-354.

[99] Gottschling, B.C., Maronpot, R.R., Hailey, J.R., Peddada, S., Moomaw, C.R., Klaunig, J.E., Nyska, A. 2001. The role of oxidative stress in indium phosphide-induced lung carcinogenesis in rats. Toxicological Sciences, 64: 28-40.

[100] Muguruma, M., Unami, A., Kanki, M., Kuroiwa, Y., Nishimura, J., Dewa, Y., Umemura, T., Oishi, Y., Mitsumori, K. 2007. Possible involvement of oxidative stress in piperonyl butoxide induced hepatocarcinogenesis in rats. Toxicology, 236: 61-75.

[101] Iqbal, M., Okazaki, Y., Okada, S. 2009. Curcumin attenuates oxidative damage in animals treated with a renal carcinogen, ferric nitrilotriacetate (Fe-NTA): implications for cancer prevention. Molecular and Cellular Biochemistry, 324: 157-164.

[102] Kumar, M., Sharma, V.L., Sehgal, A., Jain, M. 2012. Protective effects of green and white tea against benzo(a)pyrene induced oxidative stress and DNA damage in murine model. Nutrition and Cancer, 64: 300-306.

[103] Sintara, K., Thong-Ngam, D., Patumraj, S., Klaikeaw, N. 2012. Curcumin attenuates gastric cancer induced by N-methyl-N-nitrosourea and saturated sodium chloride in rats. Journal of Biomedicine and Biotechnology, 2012, Article ID 915380, 8 pages.

[104] Okado-Matsumoto, A., Fridovich, I. 2001. Subcellular distribution of superoxide dismutases (SOD) in rat liver. Journal of Biological Chemistry, 276: 38,388-38,393.

[105] Pamplona, R., Costantini, D. 2011. Molecular and structural antioxidant defenses against oxidative stress in animals. American Journal of Physiology, 301: R843-R863. 
[106] Góth, L. 2000. Lipid and carbohydrate metabolism in acatalasemia. Clinical Chemistry, 46: 560-576.

[107] Brigelius-Flohé, R., Kipp, A. 2009. Glutathione peroxidases in different stages of carcinogenesis. Biochimica et Biophysica Acta, 1790: 1555-1568.

[108] Brigelius-Flohé, R., Maiorino, M. 2013. Glutathione peroxidases. Biochimica et Biophysica Acta, 1830: 3289-3303.

[109] Arthur, J. 2000. The glutathione peroxidases. Cellular and Molecular Life Sciences, 57: $1825-1835$.

[110] Papp, L.V., Lu, J., Holmgren, A., Khanna, K.K. 2007. From selenium to selenoproteins: synthesis, identity, and their role in human health. Antioxidants \& Redox Signaling, 9: 775-806.

[111] Steinbrenner, H., Sies, H. 2009. Protection against reactive oxygen species by selenoproteins. Biochimica et Biophysica Acta, 1790: 1478-1485.

[112] Anderson, M.E. 1996. Glutathione and glutathione delivery compounds. Advances in Pharmacology, 38: 65-78.

[113] Anderson, M.E., Luo, J.L. 1998. Glutathione therapy: from prodrugs to genes. Seminars in Liver diseases, 18: 415-424.

[114] Nordberg, J., Arnér, E.S.J. 2001. Reactive oxygen species, antioxidants, and the mammalian thioredoxin system1. Free Radical Biology and Medicine, 31: 1287-1312.

[115] Rahman, Q., Abidi, P., Afaq, F., Schiffmann, D., Mossman, B.T., Kamp, D.W., Athar, M. 1999. Glutathione redox system in oxidative lung injury. Critical Reviews in Toxicology, 29: 543-568.

[116] Deneke, S.M. 2001. Thiol-based antioxidants. Current Topics in Cellular Regulation, 36: $151-180$.

[117] Suntres, Z.E. 2002. Role of antioxidants in paraquat toxicity. Toxicology, 180: 65-77.

[118] Suntres, Z.E. 2011. Liposomal antioxidants for protection against oxidant-induced damage. Journal of Toxicology, 2011, Article ID 152474, 16 pages.

[119] Dickinson, D.A., Forman, H.J. 2002. Glutathione in defense and signaling. Annal of New York Academy of Science, 973: 488-504.

[120] Marnewick, J.L., Van Der Westhuizen, F.H., Joubert, E., Swanevelder, S., Swart, P., et al. 2009. Chemoprotective properties of rooibos (Aspalathus linearis), honeybush (Cyclopia intermedia) herbal and green and black (Camellia sinensis) teas against cancer promotion induced by fumonisin B1 in rat liver. Food Chem Toxicol, 47: 220-229.

[121] Aquilano, K., Baldeli, S., Ciriolo, M.R. 2014. Glutathione: new roles in redox signaling for an old antioxidant. Frontiers in Pharmacology, 5: 196. 
[122] Hashemy, S.I. 2011. The human thioredoxin system: modifications and clinical applications. Iranian Journal of Basic Medical Sciences, 14: 191-204.

[123] Nakamura, H. 2005. Thioredoxin and its related molecules: update 2005. Antioxidants \& Redox Signaling, 7: 823-828.

[124] Karlenius, T.C., Tonissen, K.F. 2010. Thioredoxin and cancer: a role for thioredoxin in all states of tumor oxygenation. Cancers, 2: 209-232.

[125] Barja, G. 1996. Ascorbic acid and aging. Sub-cellular Biochemistry, 25: 157-188.

[126] Buettner, G.R. 1993. The Pecking order of free radicals and antioxidants: lipid peroxidation, tocopherol, and ascorbate. Archives of Biochemistry and Biophysics, 300: 535-543.

[127] Du, J., Cullen, J.J., Buettner, G.R. 2012. Ascorbic acid: chemistry, biology and the treatment of cancer. Biochimica et Biophysica Acta, 1826: 443-457.

[128] Rose, R., Bode, A. 1993. Biology of free radical scavengers: an evaluation of ascorbate. FASEB Journal, 7: 1135-1142.

[129] Navas, P., Villalba, J.M., Córdoba, F. 1994. Ascorbate function at the plasma membrane. Biochimica et Biophysica Acta, 1197: 1-13.

[130] Linster, C.L., Van Schaftingen, E. 2007. Vitamin C. FEBS Journal, 274: 1-22.

[131] Wells, W.W., Xu, D.P. 1994. Dehydroascorbate reduction. Journal of Bioenergetics and Biomembranes, 26: 369-377.

[132] Bielski, B.H.J., Allen, A.O., Schwarz, H.A. 1981. Mechanism of the disproportionation of ascorbate radicals. Journal of the American Chemical Society, 103: 3516-3518.

[133] Corti, A., Casini, A.F., Pompella, A. 2010. Cellular pathways for transport and efflux of ascorbate and dehydroascorbate. Archives of Biochemistry and Biophysics, 500: 107-115.

[134] Frei, B., England, L., Ames, B.N. 1989. Ascorbate is an outstanding antioxidant in human blood plasma. Proceedings of the National Academy of Sciences, 86: 6377-6381.

[135] Wang, X., Quinn, P.J. 1999. Vitamin E and its function in membranes. Progress in Lipid Research, 38: 309-336.

[136] Bron, D., Asmis, R. 2001. Vitamin E and the prevention of atherosclerosis. International Journal for Vitamin and Nutrition Research, 71: 18-24.

[137] Surai, P.F. 2002. Natural antioxidants in avian nutrition and reproduction. Nottingham University Press.

[138] Esterbauer, H., Schaur, R.J., Zollner, H. 1991. Chemistry and biochemistry of 4-hydroxynonenal, malonaldehyde and related aldehydes. Free Radical Biology and Medicine, 11: 81-128. 
[139] Halliwell, B. 2012. Free radicals and antioxidants: updating a personal view. Nutrition Reviews, 70: 257-265.

[140] Costantini, D., Møller, A. 2008. Carotenoids are minor antioxidants for birds. Functional Ecology, 22: 367-370.

[141] Costantini, D., Fanfani, A., Dell'Omo, G. 2008. Effects of corticosteroids on oxidative damage and circulating carotenoids in captive adult kestrels (Falco tinnunculus). Journal of Comparative Physiology B, 178: 829-835.

[142] Isaksson, C., Andersson, S. 2008. Oxidative stress does not influence carotenoid mobilization and plumage pigmentation. Proceedings of the Royal Society B, 275: 309314.

[143] Horak, P., Sild, E., Soomets, U., Sepp, T., Kilk, K. 2010. Oxidative stress and information content of black and yellow plumage coloration: an experiment with greenfinches. Journal of Experimental Biology, 213: 2225-2233.

[144] Larcombe, S.D., Mullen, W., Alexander, L., Arnold, K.E. 2010. Dietary antioxidants, lipid peroxidation and plumage colouration in nestling blue tits Cyanistes caeruleus. Naturwissenschaften, 97: 903-913.

[145] Heinonen, O.P., Albanes, D. 1994. The effect of vitamin E and beta carotene on the incidence of lung cancer and other cancers in male smokers. New England Journal of Medicine, 330: 1029-1035.

[146] Albanes, D., Heinonen, O.P., Taylor, P.R., Virtamo, J., Edwards, B.K., Rautalahti, M., et al. 1996. $\alpha$-Tocopherol and $\beta$-carotene supplements and lung cancer incidence in the $\alpha$-tocopherol, $\beta$-carotene cancer prevention study: effects of base-line characteristics and study compliance. Journal of the National Cancer Institute, 88: 1560-1570.

[147] Lee, I.M., Cook, N.R., Manson, J.A.E., Buring, J.E., Hennekens, C.H. 1999. $\beta$-carotene supplementation and incidence of cancer and cardiovascular disease: the Women's Health Study. Journal of the National Cancer Institute, 91: 2102-2106.

[148] Muntwyler, J., Hennekens, C.H., Manson, J.A.E., Buring, J.E., Gaziano, J.M. 2002. Vitamin supplement use in a low-risk population of US male physicians and subsequent cardiovascular mortality. Archives of Internal Medicine, 162: 1472-1476.

[149] Roberts, C.K., Barnard, R.J., 2005. Effects of exercise and diet on chronic disease. Journal of Applied Physiology, 98: 3-30.

[150] Martinez-Gonzalez, M.A., Bes-Rastrollo, M., Serra-Majem, L., Lairon, D., Estruch, R., Trichopoulou, A. 2009. Mediterranean food pattern and the primary prevention of chronic disease: recent developments. Nutrition Reviews, 67: S111-S116.

[151] Aggarwal, B.B., Shishodia, S., Sandur, S.K., Pandey, M.K., Sethi, G. 2006. Inflammation and cancer: how hot is the link? Biochemical Pharmacology, 72: 1605-1621. 
[152] Surh, Y.J. 2003. Cancer chemoprevention with dietary phytochemicals. Nature Reviews Cancer, 3: 768-780.

[153] Weng, C.J., Yen, G.C. 2012. Chemopreventive effects of dietary phytochemicals against cancer invasion and metastasis: phenolic acids, monophenol, polyphenol, and their derivatives. Cancer Treatment Reviews, 38: 76-87.

[154] Liu, R.H. 2003. Health benefits of fruit and vegetables are from additive and synergistic combinations of phytochemicals. American Journal of Clinical Nutrition, 78: 517S-520S.

[155] Liu, R.H. 2004. Potential synergy of phytochemicals in cancer prevention: mechanism of action. Journal of Nutrition, 134: 3479S-3485S.

[156] De Kok, T.M., Van Breda, S.G., Manson, M.M. 2008. Mechanisms of combined action of different chemopreventive dietary compounds. European Journal of Nutrition, 47: $51-59$.

[157] Crozier, A., Jaganath, I.B., Clifford, M.N. 2009. Dietary phenolics: chemistry, bioavailability and effects on health. Natural Product Reports, 26: 1001-1043.

[158] Tsao, R. 2010. Chemistry and biochemistry of dietary polyphenols. Nutrients, 2: 1231-1246.

[159] Balasundram, N., Sundram, K., Samman, S. 2006. Phenolic compounds in plants and agri-industrial by-products: antioxidant activity, occurrence, and potential uses. Food Chemistry, 99: 191-203.

[160] Taylor, L.P., Grotewold, E. 2005. Flavonoids as developmental regulators. Current Opinion in Plant Biology, 8: 317-323.

[161] Simmonds, M.S.J. 2001. Importance of flavonoids in insect-plant interactions: feeding and oviposition. Phytochemistry, 56: 245-252.

[162] Xu, C., Natarajan, S., Sullivan, J.H. 2008a. Impact of solar ultraviolet-B radiation on the antioxidant defense system in soybean lines differing in flavonoid contents. Environmental and Experimental Botany, 63: 39-48.

[163] Xu, C., Sullivan, J.H., Garrett, W.M., Caperna, T.J., Natarajan, S. 2008b. Impact of solar ultraviolet-B on the proteome in soybean lines differing in flavonoid contents. Phytochemistry, 69: 38-48.

[164] Yao, L.H., Jiang, Y.M., Shi, J., Tomas-Barberan, F.A., Datta, N., Singanusong, R., Chen, S.S. 2004. Flavonoids in food and their health benefits. Plant Foods for Human Nutrition, 59: 113-122.

[165] Lin, J., Weng, M.S. 2006. Flavonoids as nutraceuticals. The Science of Flavonoids, 213-238. 
[166] Pereira, D.M., Valentão, P., Pereira, J.A., Andrade, P.B. 2009. Phenolics: from chemistry to biology. Molecules, 14: 2202-2211.

[167] Van Wyk, B.E., Gericke, M. 2000. People's plants. A Guide to Useful Plants of Southern Africa. Briza Publications, Pretoria, South Africa, pp. 102-103.

[168] McKay, D.L., Blumberg, J.B. 2007. A review of the bioactivity of South African herbal teas: rooibos (Aspalathus linearis) and honeybush (Cyclopia intermedia). Phytotherapy Research, 21: 1-16.

[169] Van Heerden, F., Van Wyk, B.E., Viljoen, A., Steenkamp, P. 2003. Phenolic variation in wild populations of Aspalathus linearis (rooibos tea). Biochemical Systematics and Ecology, 31: 885-895.

[170] Wilson, N.L.W. 2005. Cape natural tea products and the US market: rooibos rebels ready to raid. Applied Economic Perspectives and Policy, 27: 139-148.

[171] Cheney, R.H., Scholtz, E. 1963. Rooibos tea, a South African contribution to world beverages. Economic Botany, 17: 186-194.

[172] Morton, J.F. 1983. Rooibos tea, Aspalathus linearis, a caffeineless, low-tannin beverage. Economic Botany, 37: 164-173.

[173] Joubert, E., Gelderblom, W., Louw, A., De Beer, D. 2008a. South African herbal teas: Aspalathus linearis, Cyclopia spp. and Athrixia phylicoides - a review. Journal of Ethnopharmacology, 119: 376-412.

[174] Reynecke, J., Coetzee, W., Bester, J. 1949. Rooibos tea. A preliminary report on the composition. Farming in South Africa, 24: 397-398.

[175] Blommaert, K.L.J., Steenkamp, J. 1978. Tannien- en moontlike kafeieninhoud van rooibostee, Aspalathus (Subgen. Nortiera) linearis (Burm. Fil) R. Dahlgr. Agroplantae, 10: 49 .

[176] Koeppen, B., Roux, D. 1966. C-glycosylflavonoids. The chemistry of aspalathin. Biochemical Journal, 99: 604-609.

[177] Rabe, C., Steenkamp, J.A., Joubert, E., Burger, J.F.W., Ferreira, D. 1994. Phenolic metabolites from rooibos tea (Aspalathus linearis). Phytochemistry, 35: 1559-1565.

[178] Shimamura, N., Miyase, T., Umehara, K., Warashina, T., Fujii, S. 2006. Phytoestrogens from Aspalathus linearis. Biological and Pharmaceutical Bulletin, 29: 1271-1274.

[179] Joubert, E. 1996. HPLC quantification of the dihydrochalcones, aspalathin and nothofagin in rooibos tea (Aspalathus linearis) as affected by processing. Food Chemistry, 55: 403-411.

[180] Joubert, E., Gelderblom, W., De Beer, D. 2009. Phenolic contribution of South African herbal teas to a healthy diet. Natural Product Communications, 4: 701-718. 
[181] Hillis, W., Inoue, T. 1967. The polyphenols of Nothofagus species II: the heartwood of Nothofagus fusca. Phytochemistry, 6: 59-67.

[182] Huang, C., Gan, X., Bai, H., Ma, L., Hu, L. 2008. Schoepfin A, B, C: three new chalcone C-glycosides from Schoepfia chinensis. Natural Product Research, 22: 623-627.

[183] Koeppen, B., Roux, D. 1965. C-glycosylflavonoids. The chemistry of orientin and isoorientin. Biochemical Journal, 97: 444-448.

[184] Bramati, L., Minoggio, M., Gardana, C., Simonetti, P., Mauri, P., Pietta, P. 2002. Quantitative characterization of flavonoid compounds in rooibos tea (Aspalathus linearis) by LC-UV/DAD. Journal of Agricultural and Food Chemistry, 50: 5513-5519.

[185] Snyckers, F., Salemi, G. 1974. Studies of South African medicinal plants. Part 1. Quercetin as the major in vitro active component of rooibos tea. Journal of South African Chemical Institute, 27: 5-7.

[186] Kazuno, S., Yanagida, M., Shindo, N., Murayama, K. 2005. Mass spectrometric identification and quantification of glycosyl flavonoids, including dihydrochalcones with neutral loss scan mode. Analytical Biochemistry, 347: 182-192.

[187] Krafczyk, N., Glomb, M.A. 2008. Characterization of phenolic compounds in rooibos tea. Journal of Agricultural and Food Chemistry, 56: 3368-3376.

[188] Ferreira, D., Marais, C., Steenkamp, J.A., Joubert, E. 1995. Rooibos tea as a likely health food supplement. Proceedings of Recent Development of Technologies on Fundamental Foods for Health, 73-88.

[189] Marnewick, J.L., Gelderblom, W.C.A., Joubert, E. 2000. An investigation on the antimutagenic properties of South African herbal teas. Mutation Research, 471: 157-166.

[190] Standley, L., Winterton, P., Marnewick, J.L., Gelderblom, W.C.A., Joubert, E., Britz, T.J. 2001. Influence of processing stages on antimutagenic and antioxidant potentials of rooibos tea. Journal of Agricultural and Food Chemistry, 49: 114-117.

[191] Joubert, E., Winterton, P., Britz, T.J., Gelderblom, W.C.A. 2005. Antioxidant and prooxidant activities of aqueous extracts and crude polyphenolic fractions of rooibos (Aspalathus linearis). Journal of Agricultural and Food Chemistry, 53: 10,260-10,267.

[192] Joubert, E., Ferreira, D. 1996. Antioxidants of rooibos tea - a possible explanation for its health promoting properties? South African Journal of Food Science and Nutrition, 8: 79-84.

[193] Bramati, L., Aquilano, F., Pietta, P. 2003. Unfermented rooibos tea: quantitative characterization of flavonoids by HPLC-UV and determination of the total antioxidant activity. Journal of Agricultural and Food Chemistry, 51: 7472-7474.

[194] Von Gadow, A., Joubert, E., Hansmann, C. 1997a. Comparison of the antioxidant activity of rooibos tea (Aspalathus linearis) with green, oolong and black tea. Food Chemistry, 60: 73-77. 
[195] Joubert, E., Winterton, P., Britz, T.J., Ferreira, D. 2004. Superoxide anion and $\alpha$, $\alpha$ diphenyl- $\beta$-picrylhydrazyl radical scavenging capacity of rooibos (Aspalathus linearis) aqueous extracts, crude phenolic fractions, tannin and flavonoids. Food Research International, 37: 133-138.

[196] Joubert, E., Richards, E.S., Merwe, J.D.V., De Beer, D., Manley, M., Gelderblom, W. $2008 \mathrm{~b}$. Effect of species variation and processing on phenolic composition and in vitro antioxidant activity of aqueous extracts of Cyclopia spp. (honeybush tea). Journal of Agricultural and Food Chemistry, 56: 954-963.

[197] Von Gadow, A., Joubert, E., Hansmann, C. 1997b. Effect of extraction time and additional heating on the antioxidant activity of rooibos tea (Aspalathus linearis) extracts. Journal of Agricultural and Food Chemistry, 45: 1370-1374.

[198] Snijman, P.W., Joubert, E., Ferreira, D., Li, X. C., Ding, Y., Green, I.R., Gelderblom, W.C.A. 2009. Antioxidant activity of the dihydrochalcones aspalathin and nothofagin and their corresponding flavones in relation to other rooibos (Aspalathus linearis) flavonoids, epigallocatechin gallate, and Trolox. Journal of Agricultural and Food Chemistry, 57: 6678-6684.

[199] Krafczyk, N., Heinrich, T., Porzel, A., Glomb, M.A. 2009. Oxidation of the dihydrochalcone aspalathin leads to dimerization. Journal of Agricultural and Food Chemistry, $57 ; 6838-6843$.

[200] Hitomi, E., Tamura, S., Tsurumoto, Y., Tsuda, T., Nakano, M. 1999. Antioxidative activity of rooibos tea (Aspalathuslinearis). Journal of the Japanese Society of Food Science and Technology, 46: 779-785.

[201] Marnewick, J., Joubert, E., Joseph, S., Swanevelder, S., Swart, P., Gelderblom, W. 2005. Inhibition of tumour promotion in mouse skin by extracts of rooibos (Aspalathus linearis) and honeybush (Cyclopia intermedia), unique South African herbal teas. Cancer Letters, 224: 193-202.

[202] Akaike, T., Ijiri, S., Sato, K., Maeda, H. 1995. Determination of peroxyl radical-scavenging activity in food by using bactericidal action of alkyl peroxyl radical. Journal of Agricultural and Food Chemistry, 43: 1864-1870.

[203] Lee, E.J., Jang, H.D. 2004. Antioxidant activity and protective effect on DNA strand scission of rooibos tea (Aspalathus linearis). Biofactors, 21: 285-292.

[204] Yoo, K.M., Lee, C.H., Lee, H., Moon, B.K., Lee, C.Y. 2008. Relative antioxidant and cytoprotective activities of common herbs. Food Chemistry, 106: 929-936.

[205] Inanami, O., Asanuma, T., Inukai, N., Jin, T., Shimokawa, S., Kasai, N., Nakano, M., Sato, F., Kuwabara, M. 1995. The suppression of age-related accumulation of lipid peroxides in rat brain by administration of rooibos tea (Aspalathus linearis). Neuroscience Letters, 196: 8588. 
[206] Shimoi, K., Masuda, S., Shen, B., Furugori, M., Kinae, N. 1996. Radioprotective effects of antioxidative plant flavonoids in mice. Mutation Research, 350: 153-161.

[207] Hitomi, E., Nishikiori, A., Matsumoto, A., Moriguchi, S., Kojo, S., Tokumaru, S., Nakano, M. 2004. Effect of rooibos tea (Aspalathus linearis) extract on lipid peroxidation in vitamin E deficient rats. ITE Letters on Batteries New Technologies and Medicine, 5: 30-38.

[208] Marnewick, J.L., Joubert, E., Swart, P., van der Westhuizen, F., Gelderblom, W.C. 2003. Modulation of hepatic drug metabolizing enzymes and oxidative status by rooibos (Aspalathus linearis) and honeybush (Cyclopia intermedia), green and black (Camellia sinensis) teas in rats. Journal of Agricultural and Food Chemistry, 51: 81138119.

[209] Kucharska, J., Ulicna, O., Gvozdjakova, A., Sumbalova, Z., Vancova, O., Bozek, P., Nakano, M., Greksak, M. 2004. Regeneration of coenzyme Q9 redox state and inhibition of oxidative stress by rooibos tea (Aspalathus linearis) administration in carbon tetrachloride liver damage. Physiological Research, 53: 515-522.

[210] Awoniyi, D.O., Aboua, Y.G., Marnewick, J., Brooks, N. 2012. The effects of rooibos (Aspalathus linearis), green tea (Camellia sinensis) and commercial rooibos and green tea supplements on epididymal sperm in oxidative stress-induced rats. Phytotherapy Research, 26: 1231-1239.

[211] Ajuwon, O.R., Katengua-Thamahane, E., Van Rooyen, J., Oguntibeju, O.O., Marnewick, J. 2013. Protective effects of rooibos (Aspalathus linearis) and/or red palm oil (Elaeis guineensis) supplementation on tert-butyl hydroperoxide-induced oxidative hepatotoxicity in Wistar rats. Evidence-Based Complementary and Alternative Medicine, 2013, Article ID 984273, 19 pages.

[212] Ajuwon, O.R., Oguntibeju O.O., Marnewick J.L. 2014. Amelioration of lipopolysaccharide-induced liver injury by aqueous rooibos (Aspalathus linearis) extract via inhibition of pro-inflammatory cytokines and oxidative stress. BMC Complementary and Alternative Medicine, 14: 392.

[213] Saleem, T.S.M., Chetty, C.M., Ramkanth, S., Rajan, V., Kumar, K.M., Gauthaman, K. 2010. Hepatoprotective herbs - a review. International Journal of Research in Pharmaceutical Sciences, 1: 1-5.

[214] Chen, C.J., Deng, A.J., Liu, C., Shi, R., Qin, H.L., Wang, A.P. 2011. Hepatoprotective activity of Cichorium endivia L. extract and its chemical constituents. Molecules, 16: 9049-9066.

[215] Ulicna, O., Greksák, M., Vancova, O., Zlatos, L., Galbavy, S., Bosek, P., Nakano, M. 2003. Hepatoprotective effect of rooibos tea (Aspalathus linearis) on $\mathrm{CCl}_{4}$-induced liver damage in rats. Physiological Research, 52: 461-466.

[216] Ulicna, O., Vancova, O., Waczulikova, I., Bozek, P., Janega, P., Babal, P., Liskova, S., Greksak, M. 2008. Does rooibos tea (Aspalathus linearis) support regeneration of rat 
liver after intoxication by carbon tetrachloride? General Physiology and Biophysics, 27: 179-186.

[217] McCune, L.M., Johns, T. 2002. Antioxidant activity in medicinal plants associated with the symptoms of diabetes mellitus used by the indigenous peoples of the North American boreal forest. Journal of Ethnopharmacology, 82: 197-205.

[218] Büyükbalci, A., El, S.N. 2008. Determination of in vitro antidiabetic effects, antioxidant activities and phenol contents of some herbal teas. Plant Foods for Human Nutrition, 63: 27-33.

[219] Pandey, K.B., Rizvi, S.I. 2010. Resveratrol may protect plasma proteins from oxidation under conditions of oxidative stress in vitro. Journal of the Brazilian Chemical Society, 21: 909-913.

[220] Meece, J. 2007. Pancreatic islet dysfunction in type 2 diabetes: a rational target for incretin-based therapies. Current Medicinal Research and Opinions, 23: 933-944.

[221] Wali, J.A., Rondas, D., McKenzie, M.D., Zhao, Y., Elkerbout, L., Fynch, S., Gurzov, E.N., Akira, S., Mathieu, C., Kay, T.W.H., Overbergh, L., Strasser, A., Thomas, H.E. 2014. The proapoptotic BH3-only proteins Bim and Puma are downstream of endoplasmic reticulum and mitochondrial oxidative stress in pancreatic islets in response to glucotoxicity. Cell Death and Disease, 5: e1124.

[222] Lenzen, S., Drinkgern, J., Tiedge, M. 1996. Low antioxidant enzyme gene expression in pancreatic islets compared with various other mouse tissues. Free Radical Biology and Medicine, 20: 463-466.

[223] Jonas, J.C., Bensellam, M., Duprez, J., Elouil, H., Guiot, Y., Pascal, S.M. 2009. Glucose regulation of islet stress responses and beta-cell failure in type 2 diabetes. Diabetes Obesity and Metabolism, 11(Suppl 4): 65-81.

[224] Burcelin, R., Knauf, C., Cani, P.D. 2008. Pancreatic $\alpha$-cell dysfunction in diabetes. Diabetes and Metabolism, 34: S49-S55.

[225] Diao, J., Allister, E.M., Koshkin, V., Lee, S.C., Bhattacharjee, A., Tang, C., Giacca, A., Chan, C.B., Wheeler, M.B. 2008. UCP2 is highly expressed in pancreatic $\alpha$-cells and influences secretion and survival. Proceedings of the National Academy of Sciences, 105: 12,057-12,062.

[226] Rolo, A.P., Palmeira, C.M. 2006. Diabetes and mitochondrial function: role of hyperglycemia and oxidative stress. Toxicology and Applied Pharmacology, 212: 167-178.

[227] Bloch, K., Shichman, E., Vorobeychik, M., Bloch, D., Vardi, P. 2006. Catalase expression in pancreatic alpha cells of diabetic and non-diabetic mice. Histochemistry and Cell Biology, 127: 227-232. 
[228] Van Dam, P.S., Van Asbeck B.S., Van Oirschot J.F., Biessels G.J., Hamers F.P., Marx J.J. 2001. Glutathione and $\alpha$-lipoate in diabetic rats: nerve function, blood flow and oxidative state. European Journal of Clinical Investigation, 31: 417-424.

[229] Palmer, A., Thomas, C.R., Gopaul, N., Dhir, S., Änggård, E.E., Poston, L.., Tribe, R.M. 1998. Dietary antioxidant supplementation reduces lipid peroxidation but impairs vascular function in small mesenteric arteries of the streptozotocin-diabetic rat. Diabetologia, 41: 148-156.

[230] Portero-Otín, M., Pamplona, R., Ruiz, M.C., Cabiscol, E., Prat, J., Bellmunt, M.J. 1999. Diabetes induces an impairment in the proteolytic activity against oxidized proteins and a heterogeneous effect in non-enzymatic protein modifications in the cytosol of rat liver and kidney. Diabetes 48: 2215-2220.

[231] Ling, X., Nagai, R., Sakashita, N., Takeya, M., Horiuchi, S., Takahashi, K. 2001. Immunohistochemical distribution and quantitative biochemical detection of advanced glycation end products in fetal to adult rats and in rats with streptozotocin-induced diabetes. Laboratory Investigation, 81: 845-861.

[232] Gopaul, N.K., Angglard, E.E., Mallet, A.I., Betteridge, D.J., Wolff, S.P., Nourooz-Zadeh, J. 1995. Plasma 8-epi-PGF ${ }_{2 a l p h a}$ levels are elevated in individuals with non-insulin dependent diabetes mellitus. FEBS Letters, 368: 225-229.

[233] Davi, G., Ciabattoni, G., Consoli, A., Mezzetti, A., Falco, A., Santarone, S., et al. 1999. In vivo formation of 8-iso-prostaglandin $\mathrm{F}_{2 a l p h a}$ and platelet activation in diabetes mellitus. Circulation, 99: 224-229.

[234] Martin-Gallan, P., Carrascosa, A., Gussinye, M., Dominguez, C. 2003. Biomarkers of diabetes-associated oxidative stress and antioxidant status in young diabetic patients with or without subclinical complications. Free Radical Biology and Medicine, 34: 1563-1574.

[235] Kashiba, M., Oka, J., Ichikawa, R., Kasahara, E., Inayama, T., Kageyama, A., et al. 2002. Impaired ascorbic acid metabolism in streptozotocin-induced diabetic rats. Free Radical Biology and Medicine, 33: 1221-1230.

[236] Obrosova, I.G., Fathallah, L., Liu, E., Nourooz-Zadeh, J. 2003. Early oxidative stress in the diabetic kidney: effect of DL-alpha-lipoic acid. Free Radical Biology and Medicine, 34: 186-195.

[237] Sundaram, R.K., Bhaskar, A., Vijayalingam, S., Viswanathan, M., Mohan, R., Shanmugasundaram, K.R. 1996. Antioxidant status and lipid peroxidation in type II diabetes mellitus with and without complications. Clinical Science, 90: 255-260.

[238] Nourooz-Zadeh, J., Rahimi, A., Tajaddini-Sarmadi, J., Tritschler, H., Rosen, P., Halliwell, B., et al. 1997. Relationships between plasma measures of oxidative stress and metabolic control in NIDDM. Diabetologia, 40: 647-653. 
[239] Davison, G.W., George, L., Jackson, S.K., Young, I.S., Davies, B., Bailey, D.M., et al. 2002. Exercise, free radicals, and lipid peroxidation in type 1 diabetes mellitus. Free Radical Biology and Medicine, 33: 1543-1551.

[240] Niedowicz, D.M., Daleke, D.L. 2005. The role of oxidative stress in diabetic complications. Cell Biochemistry and Biophysics, 43: 289-330.

[241] Erasto, P., Adebola, P., Grierson, D., Afolayan, A. 2005. An ethnobotanical study of plants used for the treatment of diabetes in the Eastern Cape Province, South Africa. African Journal of Biotechnology, 4: 1458-1460.

[242] Jung, M., Park, M., Lee, H.C., Kang, Y.H., Kang, E.S., Kim, S.K. 2006. Antidiabetic agents from medicinal plants. Current Medicinal Chemistry, 13: 1203-1218.

[243] Gallagher, A., Flatt, P., Duffy, G., Abdel-Wahab, Y. 2003. The effects of traditional antidiabetic plants on in vitro glucose diffusion. Nutrition Research, 23: 413-424.

[244] Kelble, A. 2005. Spices and type 2 diabetes. Nutrition and Food Science, 35: 81-87.

[245] Johnston, K., Sharp, P., Clifford, M., Morgan, L. 2005. Dietary polyphenols decrease glucose uptake by human intestinal Caco-2 cells. FEBS Letters, 579: 1653-1657.

[246] Han, X., Shen, T., Lou, H. 2007. Dietary polyphenols and their biological significance. International Journal of Molecular Sciences, 8: 950-988.

[247] Ulicna, O., Vancova, O., Bozek, P., Carsky, J., Sebekova, K., Boor, P., Nakano, M., Greksák, M. 2006. Rooibos tea (Aspalathus linearis) partially prevents oxidative stress in streptozotocin-induced diabetic rats. Physiological Research, 55: 157-164.

[248] Kinae, N., Shimoi, K., Masumori, S., Harasawa, M., Furugori, M. 1994. Suppression of the formation of advanced glycosylation products by tea extracts. In: Ho, C.-T., Osawa, T., Huang, M.-T., Rosen, R.T. (Eds.), Food Phytochemicals for Cancer Prevention II, ACS Symposium Series, vol. 547. American Chemical Society, Washington, DC, USA, pp. 68-75.

[249] Song, J., Kwon, O., Chen, S., Daruwala, R., Eck, P., Park, J.B., Levine, M. 2002. Flavonoid inhibition of SVCT1 and GLUT2, intestinal transporters for vitamin C and glucose. Journal of Biological Chemistry, 277: 15,252-15,260.

[250] Kawano, A., Nakamura, H., Hata, S., Minakawa, M., Miura, Y., Yagasaki, K. 2009. Hypoglycemic effect of aspalathin, a rooibos tea component from Aspalathus linearis, in type 2 diabetic model db/db mice. Phytomedicine, 16: 437-443.

[251] Joubert, E., De Beer, D., Malherbe, C., Louw, J., Muller, C., Gelderblom, W.C.A. 2010. Aspalathin, a rooibos dihydrochalcone C-glucoside - occurrence, bioavailability and potential health benefits. Abstract Book of the 64th Annual Meeting of the Japanese Society of Nutrition and Food Science, 22-23 May, Tokushima, Japan, p. 31. 
[252] Muller, C., Joubert, E., De Beer, D., Sanderson, M., Malherbe, C.J., Fey, S.J., Louw, J. 2012. Acute assessment of an aspalathin-enriched green rooibos (Aspalathus linearis) extract with hypoglycemic potential. Phytomedicine, 20: 32-39.

[253] Mazibuko, S.E., Muller, C.J.F., Joubert, E., De Beer, D., Johnson, R., Opoku, A.R., Louw, J. 2013. Amelioration of palmitate-induced insulin resistance in C2C12 muscle cells by rooibos (Aspalathus linearis). Phytomedicine, 20: 813-819.

[254] Sanderson, M., Mazibuko, S.E., Joubert, E., De Beer, D., Johnson, R., Pheiffer, C., Louw, J., Muller, C.J.F. 2014. Effects of fermented rooibos (Aspalathus linearis) on adipocyte differentiation. Phytomedicine, 21: 109-117.

[255] Dludla, P., Muller, C.J.F., Louw, J., Joubert, E., Salie, R., Opoku, A.R., Johnson, R. 2014. The cardioprotective effect of an aqueous extract of fermented rooibos (Aspalathus linearis) on cultured cardiomyocytes derived from diabetic rats. Phytomedicine, 21: 595-601.

[256] Ku, S.K., Kwak, S., Kim, Y., Bae, J.S. 2014. Aspalathin and nothofagin from rooibos (Aspalathus linearis) inhibits high glucose-induced inflammation in vitro and in vivo. Inflammation, 1-11.

[257] Hanhineva, K., Törrönen, R., Bondia-Pons, I., Pekkinen, J., Kolehmainen, M., Mykkänen, H., Poutanen, K. 2010. Impact of dietary polyphenols on carbohydrate metabolism. International Journal of Molecular Sciences, 11: 1365-1402.

[258] Colic, M., Pavelic, K. 2002. Molecular, cellular and medical aspects of the action of nutraceuticals and small molecules therapeutics: from chemoprevention to new drug development. Drugs under Experimental and Clinical Research, 28: 169-176.

[259] Mehta, R.G., Murillo, G., Naithani, R., Peng, X. 2010. Cancer chemoprevention by natural products: how far have we come? Pharmaceutical Research, 27: 950-961.

[260] Sasaki, Y.F., Yamada, H., Shimoi, K., Kator, K., Kinae, N. 1993. The clastogen-suppressing effects of green tea, Po-lei tea and rooibos tea in CHO cells and mice. Mutation Research, 286: 221-232.

[261] Komatsu, K., Kator, K., Mitsuda, Y., Mine, M., Okumura, Y. 1994. Inhibitory effects of rooibos tea (Aspalathus linearis) on X-ray-induced C3H10T12 cell transformation. Cancer Letters, 77: 33-38.

[262] Lamosova, D., Juráni, M., Greksák, M., Nakano, M., Vaneková, M. 1997. Effect of rooibos tea (Aspalathus linearis) on chick skeletal muscle cell growth in culture. Comparative Biochemistry and Physiology C, 116: 39-45.

[263] Van der Merwe, J., Joubert, E., Richards, E., Manley, M., Snijman, P., Marnewick, J., Gelderblom, W. 2006. A comparative study on the antimutagenic properties of aqueous extracts of Aspalathus linearis (rooibos), different Cyclopia spp. (honeybush) and Camellia sinensis teas. Mutation Research, 611: 42-53. 
[264] Platt, K.L., Edenharder, R., Aderhold, S., Muckel, E., Glatt, H. 2010. Fruits and vegetables protects against the genotoxicity of heterocyclic aromatic amines activated by human xenobiotic-metabolizing enzymes expressed in mammalian cells. Mutation Research, 703: 90-98.

[265] Sissing, L. 2008. Investigations into the cancer modulating properties of Aspalathus linearis (rooibos), Cyclopia intermedia (honeybush) and Sutherlandia frutescens (cancer bush) in oesophageal carcinogenesis. M.Sc. (Physiology) Thesis. University of the Western Cape, Bellville, South Africa.

[266] Snijman, P.W., Swanevelder, S., Joubert, E., Green, I.R., Gelderblom, W.C.A. 2007. The antimutagenic activity of the major flavonoids of rooibos (Aspalathus linearis): some dose-response effects on mutagen activation-flavonoid interactions. Mutation Research, 631: 111-123.

[267] Marnewick, J., Batenburg, W., Swart, P., Joubert, E., Swanevelder, S., Gelderblom, W. 2004. Ex vivo modulation of chemical-induced mutagenesis by subcellular liver fractions of rats treated with rooibos (Aspalathus linearis) tea, honeybush (Cyclopia intermedia) tea, as well as green and black (Camellia sinensis) teas. Mutation Research, 558: $145-154$.

[268] Petrova, A. 2009. Modulation of ultraviolet light-induced skin carcinogenesis by extracts of rooibos and honeybush using a mouse model: elucidating possible protective mechanisms. MTech (Biomedical Technology) Thesis. Cape Peninsula University of Technology, South Africa.

[269] Na, H.K., Mossanda, K.S., Lee, J.Y., Surh, Y.J. 2004. Inhibition of phorbol ester-induced COX-2 expression by some edible African plants. Biofactors, 21: 149-153.

[270] Marnewick, J.L., Van Der Westhuizen, F.H., Joubert, E., Swanevelder, S., Swart, P., Gelderblom, W.C.A. 2009. Chemoprotective properties of rooibos (Aspalathus linearis), honeybush (Cyclopia intermedia) herbal and green and black (Camellia sinensis) teas against cancer promotion induced by fumonisin B1 in rat liver. Food and Chemical Toxicology, 47: 220-229.

[271] Sissing, L., Marnewick, J., de Kock, M., Swanevelder, S., Joubert, E., Gelderblom, W. 2011. Modulating effects of rooibos and honeybush herbal teas on the development of esophageal papillomas in rats. Nutrition and Cancer, 63: 600-610.

[272] Mueller, M., Hobiger, S., Jungbauer, A. 2010. Anti-inflammatory activity of extracts from fruits, herbs and spices. Food Chemistry, 122: 987-996.

[273] MacNee, W. 2001. Oxidative stress and lung inflammation in airways disease. European Journal of Pharmacology, 429: 195-207.

[274] Rahman, I. 2002. Oxidative stress, transcription factors and chromatin remodelling in lung inflammation. Biochemical Pharmacology, 64: 935-942. 
[275] Baba, H., Ohtsuka, Y., Haruna, H., Lee, T., Nagata, S., Maeda, M., Yamashiro, Y., Shimizu, T. 2009. Studies of anti-inflammatory effects of rooibos tea in rats. Pediatrics International, 51: 700-704.

[276] Katengua-Thamahane, E., Marnewick, J.L., Ajuwon, O.R., Chegou, N.N., Szűcs, G., Ferdinandy, P., Csont, T., Csonka, C., Van Rooyen, J. 2014. The combination of red palm oil and rooibos show anti-inflammatory effects in rats. Journal of Inflammation, 11: 41 .

[277] Lee, W., Bae, J.S. 2015. Anti-inflammatory effects of aspalathin and nothofagin from rooibos (Aspalathus linearis) in vitro and in vivo. Inflammation, 1-15.

[278] Hesseling, P., Klopper, J., Van Heerden, P. 1979. The effect of rooibos tea on iron absorption. South African Medical Journal, 55: 631-632.

[279] Breet, P., Kruger, H.S., Jerling, J.C., Oosthuizen, W. 2005. Actions of black tea and rooibos on iron status of primary school children. Nutrition Research, 25: 983-994.

[280] Hesseling, P., Joubert, J. 1982. The effect of rooibos tea on the type I allergic reaction. South African Medical Journal, 62: 1037-1038.

[281] Shindo, Y., Kato, K. 1991. Effect of rooibos tea on some dermatological diseases. In: Proceedings of the International Symposium on Tea Science, 385-389, Shizuoka, Japan.

[282] Chuarienthong, P., Lourith, N., Leelapornpisid, P. 2010. Clinical efficacy comparison of antiwrinkle cosmetics containing herbal flavonoids. International Journal of Cosmetic Science, 32: 99-106.

[283] Glynn, K.M. 2010. From in-vitro to in-vivo: corporate development and efficacy of a topical hair growth agent derived from natural extracts. MSc (Biology) Thesis. Grand Valley State University, MI, USA.

[284] Sauter, W. 2005. Vergleich antioxidativer Eigenschaften von Extrakten aus Camellia sinensis, Rosmarinus officinalis, Cyclopia genistoides, Cyclopia sessiliflora und Aspalathus linearis. PhD Desertation. Technische Universität München, Munchen, Germany.

[285] Nikolova, V., Petrova, S., Petkova, V., Pavlova, S., Michailova, A., Georgieva, T. 2007. Antioxidative effects of rooibos tea on workers occupationally exposed to lead. Toxicology Letters, 172: S120-S121.

[286] Francisco, N.M. 2010. Modulation of postprandial oxidative stress by rooibos (Aspalathus linearis) in normolipidaemic individuals. MTech (Biomedical Technology) Thesis. Cape Peninsula University of Technology, South Africa.

[287] Guerreiro, S., Alcada, M., Azevedo, I. 2010. Bebidas acucaradas e glicemia. Acta Medica Portuguesa, 23, 567-578 (In Portuguese).

[288] Villaño, D., Pecorari, M., Testa, M.F., Raguzzini, A., Stalmach, A., Crozier, A., Tubili, C., Serafini, M. 2010. Unfermented and fermented rooibos teas (Aspalathus linearis) in- 
crease plasma total antioxidant capacity in healthy humans. Food Chemistry, 123: 679-683.

[289] Marnewick, J.L., Rautenbach, F., Venter, I., Neethling, H., Blackhurst, D.M., Wolmarans, P., Macharia, M. 2011. Effects of rooibos (Aspalathus linearis) on oxidative stress and biochemical parameters in adults at risk for cardiovascular disease. Journal of Ethnopharmacology, 133: 46-52.

[290] Persson, I.A.L., Persson, K., Hagg, S., Andersson, R.G.G. 2010. Effects of green tea, black tea and rooibos tea on angiotensin-converting enzyme and nitric oxide in healthy volunteers. Public Health Nutrition, 13: 730-737.

[291] Sinisalo, M., Enkovaara, A-L., Kivisto, K.T. 2010. Possible hepatotoxic effect of rooibos tea: a case report. European Journal of Clinical Pharmacology, 66: 427-428.

[292] Engels, M., Wang, C., Matoso, A., Maidan, E., Wands, J. 2013. Tea not tincture: hepatotoxicity associated with rooibos herbal tea. ACG Case Reports Journal, 1: 58-60. 